\title{
Cannabinoids in the landscape of cancer
}

\author{
Nagina Mangal $^{1,2} \cdot$ Simon Erridge ${ }^{1} \cdot$ Nagy Habib $^{1} \cdot$ Anguraj Sadanandam $^{2} \cdot$ Vikash Reebye $^{1} \cdot$ Mikael Hans Sodergren $^{1}$
}

Received: 19 April 2021 / Accepted: 4 June 2021 / Published online: 14 July 2021

(c) The Author(s) 2021

\begin{abstract}
Introduction Cannabinoids are a group of terpenophenolic compounds derived from the Cannabis sativa L. plant. There is a growing body of evidence from cell culture and animal studies in support of cannabinoids possessing anticancer properties. Method A database search of peer reviewed articles published in English as full texts between January 1970 and April 2021 in Google Scholar, MEDLINE, PubMed and Web of Science was undertaken. References of relevant literature were searched to identify additional studies to construct a narrative literature review of oncological effects of cannabinoids in pre-clinical and clinical studies in various cancer types.

Results Phyto-, endogenous and synthetic cannabinoids demonstrated antitumour effects both in vitro and in vivo. However, these effects are dependent on cancer type, the concentration and preparation of the cannabinoid and the abundance of receptor targets. The mechanism of action of synthetic cannabinoids, (-)-trans- $\Delta^{9}$-tetrahydrocannabinol $\left(\Delta^{9}-\mathrm{THC}\right)$ and cannabidiol (CBD) has mainly been described via the traditional cannabinoid receptors; $\mathrm{CB}_{1}$ and $\mathrm{CB}_{2}$, but reports have also indicated evidence of activity through GPR55, TRPM8 and other ion channels including TRPA1, TRPV1 and TRPV2. Conclusion Cannabinoids have shown to be efficacious both as a single agent and in combination with antineoplastic drugs. These effects have occurred through various receptors and ligands and modulation of signalling pathways involved in hallmarks of cancer pathology. There is a need for further studies to characterise its mode of action at the molecular level and to delineate efficacious dosage and route of administration in addition to synergistic regimes.
\end{abstract}

Keywords Cannabinoids $\cdot$ Cancer $\cdot$ Cannabidiol $\cdot$ Tetrahydrocannabinol $\cdot$ Cannabinoid receptors $\cdot$ Endocannabinoid system

\section{Introduction}

Since time immemorial, the Cannabis plant has been used as a source of fibre, herbal remedy, medicinal and religious purposes (Kalant 2001; Goncalves et al. 2020). In the mid-nineteenth century, O'Shaughnessy and Moreau reported positive effects of cannabis on muscle spasms, vomiting, convulsions, rheumatism, tetanus, and rabies (O'Shaughnessy 1843; Zuardi 2006). However, during the twentieth century, its utilisation in Western medicine started to decline as a result of political prejudices and economic

Mikael Hans Sodergren

m.sodergren@imperial.ac.uk

1 Medical Cannabis Research Group, Department of Surgery and Cancer, Imperial College London, Hammersmith Campus, London W12 0HS, UK

2 Systems and Precision Cancer Medicine Team, Division of Molecular Pathology, Institute of Cancer Research, London SM2 5NG, UK interests rather than scientific or medical reasons (Zuardi 2006). Over recent years, cannabis and its derivatives have been used for treating chemotherapy induced nausea and vomiting, epilepsy and multiple sclerosis amongst other indications (Parker et al. 2011; Kleckner 2019). Increasing data from and in vivo studies have started to show evidence of cannabis in modulating signalling pathways involved in cancer cell proliferation, autophagy, apoptosis and inhibition of angiogenesis and metastasis (Velasco et al. 2016). Emerging reports have also indicated synergistic effects of cannabinoids in combination with antineoplastic drugs (Moreno et al. 2019; Dariš et al. 2019; Fogli et al. 2006; Velasco et al. 2012).

The cannabis plant has been termed as a "storehouse" of several pharmacologically relevant compounds (Andre et al. 2016). The unique qualities of each cannabis variety or chemovar are the result of varying concentrations of numerous classes of bioactive molecules, most notably, cannabinoids as shown in Fig. 1, terpenoids and flavonoids (Chakravarti et al. 2014). Cannabinoids interact directly 


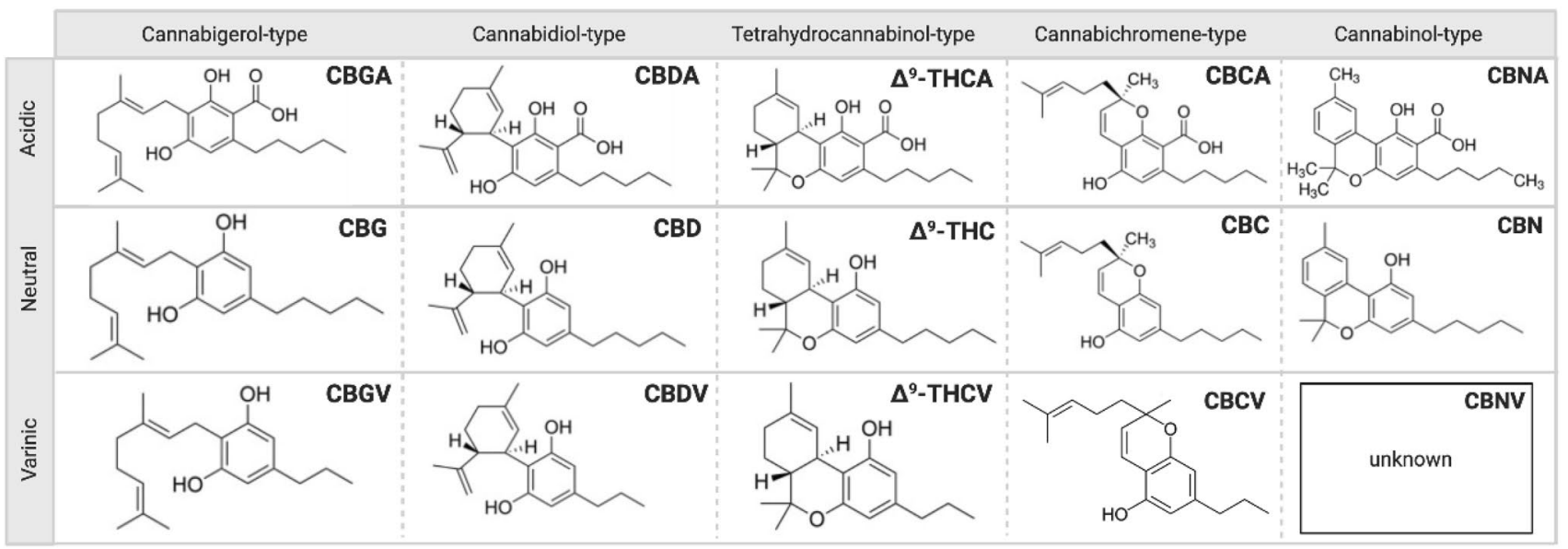

Fig. 1 The chemical structures of Cannabigerol (CBG), Cannabidiol (CBD), Tetrahydrocannabinol $\left(\Delta^{9}\right.$-THC), Cannabichromene (CBC) and Cannabinol (CBN)-type neutral, varinic and acidic phytocannabinoids. More than 120 phytocannabinoids have been isolated from Cannabis sativa $\mathrm{L}$. which can be distinguished into eleven chemical subtypes (Gonçalves et al. 2020; ElSohly 2017). Their common

with cannabinoid receptors, which include G-protein coupled receptors (cannabinoid receptor $1, \mathrm{CB}_{1}$ and cannabinoid receptor $2, \mathrm{CB}_{2}$ ), ligand-gated ion channels (i.e. vanilloid cell surface channels) and nuclear receptors (i.e. peroxisome proliferator-activated receptor gamma, PPAR $\gamma$ ) (Moreno et al. 2019; Śledziński et al. 2018) comprising the endogenous endocannabinoid system (ECS) (Zou and Kumar 2018). Three major classifications of cannabinoids include phytocannabinoids (plant-based), such as $\Delta^{9}$-tetrahydrocannabinol $\left(\Delta^{9}\right.$-THC) and cannabidiol (CBD), endocannabinoids (or endogenous cannabinoids) which include anandamide (AEA) and 2-arachidonolyglycerol (2-AG) and synthetic cannabinoids that mimic the cannabinoid groups (1) and (2) (Pertwee 2006; Lu and Mackie 2016). Endocannabinoids play a crucial role in mediating physiological functions including metabolic, cardiovascular regulation, reproduction, inflammatory response, immune system and analgesia (Guindon and Hohmann 2012; Kaur et al. 2016). AEA and 2-AG are degraded by fatty acid amide hydrolase (FAAH) and monoacylglycerol lipase (MAGL) enzymes (Pisanti et al. 2013). Modulation of their activity may have potential therapeutic implications and inhibitors are under active investigation as pharmaceuticals. Synthetic cannabinoids have been studied extensively and some have been shown to be highly bioactive than their natural counterparts, some common ones include WIN55, 212-2 (potent $\mathrm{CB}_{1}$ receptor agonist), JWH-018, JWH-073, JWH-133 (CB receptor agonists) and SR141716 or Rimonabant $\left(\mathrm{CB}_{1}\right.$ receptor antagonist) (Morales et al. 2017), overview shown in Fig. 2.

Several studies have reported the varying affinities of phytocannabinoids for the classical $\mathrm{CB}_{1}$ and $\mathrm{CB}_{2}$ receptors chemical features include a dibenzopyran ring and a hydrophobic alkyl chain (Morales et al. 2017). Aside from $\Delta^{9}$-THC and CBD, there has been a current focus on the therapeutic properties of some minor, varinic and acidic cannabinoids (Andre et al. 2016; Franco et al. 2020). Created with BioRender.com

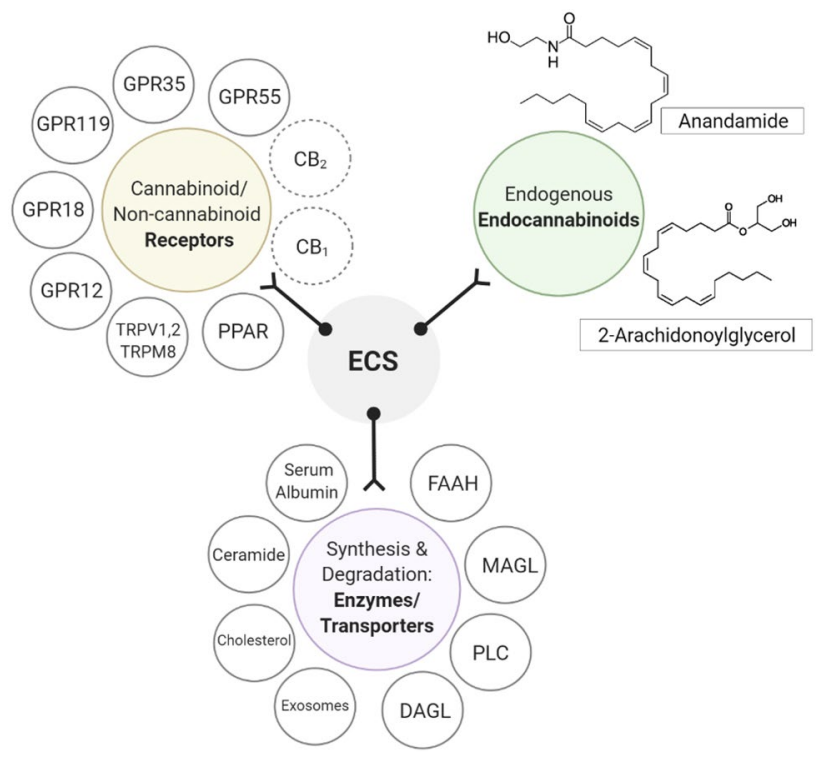

Fig. 2 Overview of the components of the endocannabinoid system (ECS) which include endogenous endocannabinoids; Anandamide (AEA) and 2-Arachidonoylglycerol (2-AG), its major receptors classified into cannabinoid receptors 1 and 2, and non-cannabinoid receptors; GPR55, GPR35, GPR119, GPR18, GPR12, ion channels including transient receptor potential cation channel subfamily members; TRPM8, TRPV1, TRPV2, peroxisome-proliferator-activated receptors (PPAR). A third component of the system are its enzymes/transporters responsible for the synthesis and degradation of endocannabinoids including serum albumin, ceramide, cholesterol, diacylglycerol lipase (DAGL), phospholipase C (PLC), monoacylglycerol lipase (MAGL), fatty acid amide hydrolase (FAAH). Created with BioRender.com 
with agonistic and antagonistic behaviours (Morales et al. 2017; Zhao and Abood 2013). However, it is now emerging that cannabinoids can interact with multiple orphan G-protein coupled receptors (GPCRs) including GPR12, GPR18, GPR35, GPR55, GPR119, opioid and serotonin receptors (Morales et al. 2017; Zhao and Abood 2013; Console-Bram et al. 2014; Brown et al. 2017; Soderstorm et al. 2017; Ferro et al. 2018; Guerrero-Alba 2019). The interaction of GPCRs is crucial for maintaining the ECS as it allows the production of endocannabinoids from cells through activation of $G_{\mathrm{q} / 11}$ or $G_{\mathrm{s}}$ proteins causing the activation of the cannabinoid receptor (Gyombolai et al. 2012). Furthermore, the downstream receptor-mediated effects of endocannabinoids also contribute to the plasticity of the ECS (Lu and Mackie 2016).

Since the first report of cannabinoids anticancer effects (Munson et al. 1975), there have been many studies investigating phytocannabinoids, endogenous and synthetic ones in multiple cancer models. Various signalling pathways and changes to internal conditions which favour antitumour activity by cannabinoids have been observed. CBD amongst other cannabinoids has shown to increase the de novo synthesis of ceramide through upregulation of a plethora of enzymes each catalysing specific biochemical steps. Ceramide synthases are one of the major group of enzymes involved and reports have revealed an upregulation of its six isoforms; CerS 1-6 (Ceramide Synthases 1-6) in cancer via cannabinoids (Gomez et al. 2002; Gustafsson et al. 2009; Schiffman et al. 2009). However, it is not clear whether specific isoform(s) upregulation correlates to the cancer type and whether this is also specific to the type of cannabinoid. An interesting finding from a report has shown siRNA-induced knockdown of ceramide synthase 1 (CerS1 isoform) prevented gemcitabineinduced caspase 9 activation (Senkal et al. 2007; Levy and Futerman 2010). This could be explored further when considering cannabinoids action synergistically with chemotherapy drugs as ceramide may have the ability to sensitize the cancer cells to chemotherapy agents. Another major area of cannabinoids action has been through modulating the cell cycle. In a recent report in gastric cancer cells, CBD-induced cell cycle arrest at the $G_{0}-G_{1}$ phase and retardation in this phase corresponded to a reduction in CDK2/cyclin E protein levels (Zhang et al. 2019). Apoptotic changes are prevalent in cannabinoids mechanism of action which include morphological changes to the cells and cytoplasmic vacuolization, an increase in cleaved caspase- 3 and -9 levels and activation of the mitochondrial apoptotic pathway (Zhang et al. 2019; Schoeman et al. 2020). Endoplasmic reticulum (ER) stress which occurs following ceramide synthesis causes downstream apoptotic changes and increases in proapoptotic proteins, such as $\mathrm{BAD}$ and $\mathrm{Bax}$, also resulting in an increase in reactive oxygen species (ROS) signalling (Zhang et al. 2019). $\Delta^{9}$ THC in glioma cells has shown to induce upregulation of the $\mathrm{p} 8$ protein (involved in ER stress and metastasis) via de novo synthesis of ceramide (Carracedo et al. 2006). From the literature available, it is evident that there is an interplay between cannabinoids downstream effects.

Overall cannabinoids induce apoptosis to inhibit proliferation, downregulate the vascular endothelial growth factor (VEGF) pathway affecting angiogenesis and dampen metastasis by inhibiting cell adhesion and migration through modifying matrix metalloproteinase 2, 9 (MMP2, 9), tissue inhibitor of matrix metalloproteinases 1 (TIMP1), inhibitor of DNA binding 1 (ID1) and inducing ER stress (Velasco et al. 2016). Cancer cells do not exist in isolation and the tumour microenvironment (TME) has also been an imperative target for cancer therapy as it can influence the propensity for tumour growth, metastasis and resistance to therapy. The TME is composed of a host of factors including cancer-associated fibroblasts (CAFs), immune and inflammatory cells, lymph and blood vasculature, neuroendocrine cells, and extracellular matrix (ECM) (Wang et al. 2017). Cancer stem cells (CSCs), a subpopulation of stem cells expressing CD44, CD24 and CD133, are tumorigenic with demonstrated resistance to certain chemotherapeutics and also play a role in metastasis (Yu et al. 2012). Reports have shown the involvement of cannabinoids in inhibiting CAFs and CSCs in prostate and breast cancer models (Sharma et al. 2014; Mohammadpour et al. 2017; Pietrovito et al. 2020). The aforementioned effects, however, occur at varying degrees which depend on the cancer cell line, the expression levels of cannabinoid receptors, the type of cannabinoid compound and dosage.

The aim of this review is to analyse pre-clinical work and outline previous and forthcoming clinical research studies exploring cannabinoids in cancer treatment. Below, we outline the research encompassing endogenous and non-endogenous cannabinoids in which we review the proposed mechanisms of action culminated from studies into various cancers and discuss the need for more clinical studies to explore the possible therapeutic efficacy of cannabinoids as a possible treatment for cancer.

\section{Method}

\section{Research question}

This narrative review was conducted of available literature reporting the treatment effects of all cannabinoids as either a single agent or co-administered with other antitumour therapies in all cancer types. The aim of this review is 
to analyse and evaluate pre-clinical and clinical research determining the use of cannabinoids as a potential anticancer therapy.

\section{Search strategy and inclusion criteria}

A broad electronic search was conducted on Google Scholar, MEDLINE, PubMed and Web of Science articles published in English between 1st January 1970 and 30th April 2021. Investigations of cannabinoids use in oncology clinical trials were searched using the database, clinicaltrials.gov.uk with the key words; "Cannabinoids and Cancer", "Cannabis and Cancer", "Tetrahydrocannabinol and Cancer", "CBD and Cancer" and "THC and Cancer". The literature search was performed by two independent researchers (N.M. and S.E.) and if any discrepancies were identified then these were resolved by a senior author (M.S.). The reference lists of all publications were screened for further relevant references. The free text search included articles citing both original research and literature reviews. Inclusion criteria encompassed all reports identifying cannabinoids use in preclinical cancer models which includes in vitro, in vivo and in ovo experimental models, as well as clinical research. In addition, reports of potential mechanisms of action and signalling pathways involved were also included. Where literature reviews were identified, the relevant cited studies were also identified and included for de novo analysis.

\section{Data extraction and presentation}

Two independent researchers (N.M. and S.E.) performed the data extraction. Primary research papers reporting half maximal inhibitory concentration $\left(\mathrm{IC}_{50}\right)$ and concentrations where the described effects were observed in pre-clinical cancer models were included in separate tables for in vitro and in vivo investigations. Concentration values are presented as micro-molar concentrations $(\mu \mathrm{M})$ with their standard deviation (S.D.), standard error (S.E), or range except when unreported in the original study.

\section{Results}

\section{Mechanism of action and signalling pathways}

The ECS is a complex system composed of different ligands, receptors and ion channels resulting in many signalling pathways subject to modulation from external cannabinoids as shown in Fig. 3. It is therefore no surprise that there remains ambiguity in its precise role within cancer pathophysiology (Wu 2019). Many pre-clinical studies and histological analysis of patient tumours, suggest that an upregulation in the $\mathrm{CB}_{1}$ and $\mathrm{CB}_{2}$ receptors, endogenous ligands and over-activation of the ECS correlates with more aggressive tumours (Dariš et al. 2019) although other reports have concluded the contrary (Jung et al. 2013; Tutino et al. 2019). Cancer is a heterogenous disease and current evidence should be interpreted on the basis that different tumour types have been shown to exhibit various levels of CB receptors as well as ECS components. The role of the endogenous endocannabinoids and CB receptors within each cancer system is specific to the underlying cancer, therefore conflicting data can be presented across different cancers. It has also been reported that some cannabinoids have shown oncological effects independent of known CB receptors (Moreno et al. 2019; Fogli et al. 2006) implying that there may be undiscovered cannabinoid receptors implicated in cancer pathophysiology.

The characterisation of cannabinoids mechanism of action has been discerned from in vitro and in vivo studies. Reports of their oncological effects have been observed through modulating the hallmarks of cancer (Hanahan and Weinberg 2000, 2011) whilst $\Delta^{9}$-THC trends in inducing apoptosis and cytotoxicity through CB receptor-dependent pathways; CBD exhibits its activity via orphan GPCRs and non-GPRCs-mediated signalling (Velasco et al. 2012, 2016; Afrin et al. 2020).

Studies have reported positive upregulation of ceramide sphingolipid metabolism, leading to the subsequent arrest of the cell cycle and apoptosis via downstream activation of signals through extracellular regulated kinase (ERK) upon cannabinoid action (Calvaruso et al. 2012). Additional studies have also concluded $\Delta^{9}$-THC's role in regulating sphingolipid metabolism via serine palmitoyl transferase (SPT) (Śledziński et al. 2018) and recent reports have concluded other enzymes of the metabolism of sphingolipids to be regulated by cannabinoids (Shaw et al. 2018). Dihydroceramides which are metabolic intermediates of the de novo synthesis pathway have been involved in the mechanisms of promoting autophagy-mediated cancer cell death (Hernández-Tiedra et al. 2016). $\Delta^{9}$-THC increases the dihydroceramide:ceramide ratio in the endoplasmic reticulum of glioma cells causing pre-apoptotic changes (Hernández-Tiedra et al. 2016).

Activation of the CB receptors causes the induction of the ER stress-related response and promotes the upregulation of the transcription factor p8 (Nupr1), this further simulates the following transcription factors, activating transcription factor 4 (ATF-4), C/EBP-homologous protein (CHOP) and pseudokinase tribbles-homologue 3 (TRIB3) (Velasco et al. 2016). The inhibitory interaction of TRIB3 and a pro-survival kinase Akt is favoured which leads to the inhibition of the mammalian target of rapamycin target 1 (mTORC1) favouring cell autophagy. Autophagy is upstream of apoptosis in cannabinoid-induced cell death as shown in studies where blocking autophagy prevented 


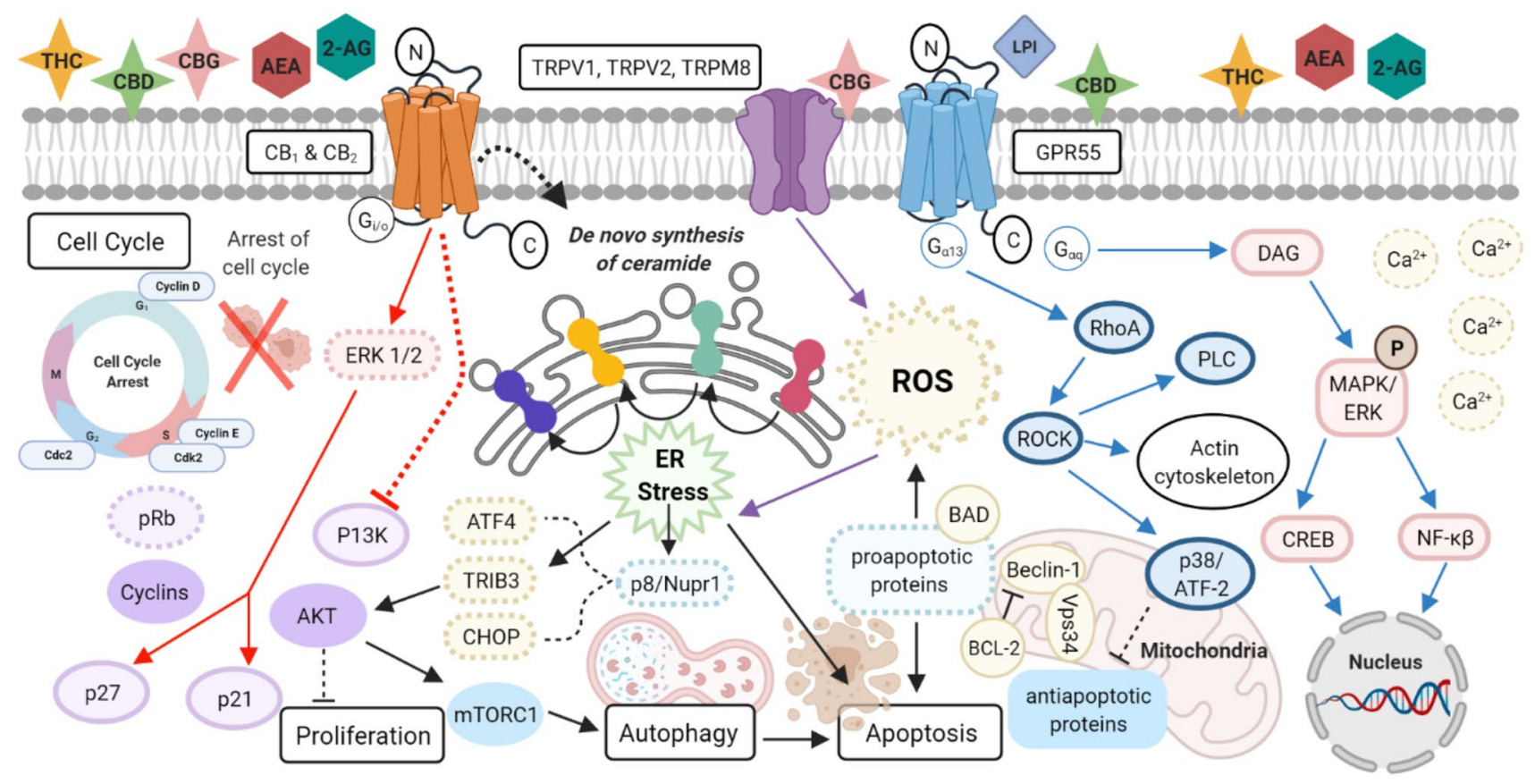

Fig. 3 Overview of the downstream activation and crosstalk of signalling pathways of cannabinoid and non-cannabinoid receptors. Activation of the cannabinoid receptors $\mathrm{CB}_{1}$ and $\mathrm{CB}_{2}$ (red arrows) via cannabinoids stimulate ERK1/2 signalling which activates p27 and p21 causing a decrease in cyclins D and E, cdc2 and cdk2 through an increase in $\mathrm{pRb}$, leading to cell cycle arrest. Inhibition of the P13K pathway leads to a decrease in Akt which inhibits cell proliferation. Biosynthesis of ceramide takes place at the endoplasmic reticulum through a series of biochemical steps involving many enzymes which help to convert dihydroceramides (DhCers) into ceramide. An increase in ceramide level in turn increases the stress protein $\mathrm{p} 8$ / Nupr1 and TRIB3 which activates upregulation of ATF4 and CHOP proteins. A decrease in Akt leads to a downregulation in mTORC1 signalling causing autophagy. Activation of TRPM8 (purple arrows) leads to an increase in ROS production which also induces ER stress. Stimulation of non-cannabinoid receptor GPR55 (blue arrows) through LPI via the subunit $\mathrm{G} \alpha_{\mathrm{q}}$ subunit stimulates the production of PLC to release $\mathrm{Ca}^{2+}$ and DAG which leads to the activation of MAPK/ERK signalling. This causes gene transcription by activation

cannabinoid-induced apoptosis (Salazar et al. 2009; Vara et al. 2011). An increase in ceramide level has also been associated with ER stress in cannabinoid-induced apoptosis in tumour cells (Salazar et al. 2009). In addition, other environmental stimuli may also promote ER stress which can lead to the activation of the apoptotic pathway. These include a decrease in intracellular $\mathrm{Ca}^{2+}$, viral infections, chemotherapy agents and oxidative stress (Schröder and Kaufman 2005; Śledziński et al. 2018).

The mitogen-activated protein kinase (MAPK) pathway has also been reported in numerous studies to be involved in cannabinoid response. Serine/threonine protein kinases are mainly involved in this pathway and act to convert extracellular stress into different cellular responses including, cell cycle arrest, apoptotic cell death and cytokine production via of transcription factors CREB and NF- $\kappa \beta . \mathrm{G}_{12 / 13}$ subunit activates the RhoA/ROCK pathway which regulates PLC, actin cytoskeleton and p38/ATF2 activity. ATF2/p38 inhibits antiapoptotic proteins and enhances the interaction between Beclin-1 and Vps34 which is also inhibited by BCL-2 further enhancing ROS production by activation of the intrinsic apoptotic pathway (Velasco et al. 2012, 2016). Created with BioRender.com. TRPV1,2 transient receptor potential cation channel subfamily $\mathrm{V}$ member 1,2 , TRPM 8 transient receptor potential cation channel subfamily members (melastatin) 8, GPR55 orphan G-protein coupled receptor 55, ROS reactive oxygen species, ER endoplasmic reticulum, $p 8$ protein $\mathrm{p} 8$ (Nuclear Protein 1, NUPR1), CHOP CCAAT/-enhancer-binding protein homologous protein, ATF4 activating transcription factor $4, T R I B 3$ tribbles pseudokinase $3, A k t$ protein kinase $\mathrm{B}$, mTORC1 mammalian target of rapamycin $\mathrm{C} 1, p 21$ cyclin-dependent kinase inhibitor 1, p27 cyclin-dependent kinase inhibitor $1 \mathrm{~B}, C D K$ cyclin-dependent kinase, $p R b$ retinoblastoma protein; Nuclear factor-kappaß (NF-кß), LPI Lysophosphatidylinositol, $D A G$ diacylglycerol, $B A D$ BCL2-associated agonist of cell death, $R O C K$ rho-associated protein kinase, $P L C$ phospholipase $\mathrm{C}$

phosphorylation. The involvement of the MAPK pathway in cancer is complex as its response to different stimuli can produce conflicting outcomes. Brief activation of the ERK cascade leads to cell survival and proliferation, whilst chronic activation is pro-apoptotic (Howlett 2005; Javid et al. 2016).

CBD has been demonstrated to affect a diverse set of cellular targets. First, it inhibits FAAH and FABP (Fatty AcidBinding Protein). FAAH is responsible for the breakdown of anandamide, whilst FABP aids the transport of anandamide to from extracellular spaces to intracellular targets, such FAAH or nuclear PPAR. Both effects result in indirect activation of $\mathrm{CB}_{1}$ and $\mathrm{CB}_{2}$ receptors through increased extracellular concentration of anandamide (Lee et al. 2007; Pistis and O'Sullivan 2017). Second, CBD activates the $5-\mathrm{HT}_{1 \mathrm{~A}}$ serotonin receptor, PPAR $\gamma$ and the transient receptor 
potential cation subfamily channels; TRPV1, TRPV2 and TRPA1. CBD is also an antagonist of GPR55, transient receptor potential cation channel subfamily $M$ member 8 (TRPM8) and T-type $\mathrm{Ca}^{2+}$ channels. Finally, $\mathrm{CBD}$ has also been reported to inhibit adenosine reuptake via multiple proposed mechanisms (Lee et al. 2007; Ibeas Bih et al. 2015; McPartland 2018). Antagonization of GPR55 via CBD has been reported to reduce proliferation of pancreatic tumour cells and its activation has been reported to lead to metastasis in triple-negative breast cancer when stimulated by LPI (Zhao and Abood 2013; Ferro et al. 2018; Andradas et al. 2016; Falasca and Ferro et al. 2018; Pellati et al. 2018). Below we summarise pre-clinical studies which include both in vitro and in vivo experimental results in various cancer models with summaries included in Tables 1 and 2.

\section{Pancreatic adenocarcinoma}

\section{In vitro}

A study analysing the in vitro effects of synthetic receptor agonists of $\mathrm{CB}_{1}$ and $\mathrm{CB}_{2}$, WIN55, 212-2, ACEA and JWH015 found they each induced a high level of apoptosis of MIA PaCa-2 cells (Console-Bram et al. 2014). The same study showed that a $\mathrm{CB}_{1}$ antagonist, $N$-(piperidin-1-1yl)5-(4-iodophenyl)-1-(2,4-dichlorophenyl)-4-methyl-1H-pyrazole-3-carboxamide (AM251), induced apoptosis and transcriptional changes of the genes involved in the janus kinase/ signal transducers, activators of transcription signalling network (JAK/STAT) and MAPK signalling pathways in the MIA PaCa-2 pancreatic cancer cell line through activation independent of the $\mathrm{CB}_{1}$ receptor-independent pathways (Fogli et al. 2006). AM251, which expresses molecular similarities with cyclo-oxygenase-2 (COX-2) inhibitor celecoxib, demonstrated a synergistic interaction with 5-fluorouracil (5-FU) increasing their anti-cancer activity when administered in appropriate ratios as demonstrated by a combination index of 0.52 (Fogli et al. 2006).

Dando et al. report arachidonoyl cyclopropylamide (ACPA) and $\mathrm{GW}, \mathrm{CB}_{1}$ and $\mathrm{CB}_{2}$ selective agonists, respectively, inhibited proliferation and invasion of PANC-1 cells (Dando et al. 2013). Activation of the receptors via cannabinoid receptor agonists showed an elevation in $5^{\prime}$ adenosine monophosphate-activated protein kinase (APMK) activation via a ROS-dependent increase of AMP/ATP ratio promoting cell autophagy and subsequent inhibition of cell growth (Dando et al. 2013; Brandi et al. 2013). $\Delta^{9}$-THC has been shown to induce a reduction in cell viability via apoptosis in a dose-dependent manner, specifically via the de novo synthesized ceramide up-regulation of the $\mathrm{p} 8$ and ATF-4, TRIB3 ER stress genes in MIA PaCa-2 and PANC-1 cells (Carracedo et al. 2006). The $\mathrm{p} 8$ protein has been shown to increase with ceramide treatment and potentiates anticancer effects (Javid et al. 2016). In support of this, MIA PaCa-2 cells treated with $\Delta^{9}$-THC caused an increase in $\mathrm{p} 8 \mathrm{mRNA}$ levels in vitro. Knockdown of the p8 gene prevented apoptosis by $\Delta^{9}$-THC in these cells (Carracedo et al. 2006). In addition to $\mathrm{p} 8$ and TRIB3 stress-related genes, further ER stress-inducing genes have been identified and associated with apoptosis, such as CHOP and ATF-4, where mRNA levels were elevated following $\Delta^{9}$-THC treatment (Ohoko et al. 2005).

Cannabinoids in combination with chemotherapy agents have shown promising results in pancreatic cancer cell line studies. One study reported the increase in gemcitabine activity by synergism with $\mathrm{CB}_{1}$ and $\mathrm{CB}_{2}$ receptor ligands by a NF- $\mathrm{K} ß$-dependent mechanism (Donadelli et al. 2011). This synergistic inhibition of tumour growth was most marked in gemcitabine-resistant cell lines (Donadelli et al. 2011). Gemcitabine increased cannabinoid-induced autophagy through a ROS-mediated mechanism and cannabinoids enhanced the apoptotic effect of gemcitabine (Donadelli et al. 2011). Ferro and co-workers reported the anticancer effects of blocking the putative GPR55 receptor in pancreatic cancer cells via CBD. A cross between GPR55 homozygous knockout and mice which do not harbour the TP53 mutation did not reveal any statistical difference in survival. Investigators analysed the possible role that p53 may play in regulating GPR55. In pancreatic ductal adenocarcinoma cell lines, they report a negative regulation of GPR55 with TP53 status, where overexpression of wild-type p53 in the AsPC-1 cell line (harbouring a TP53 mutation) caused a reduction in GPR55 expression. Further analysis revealed the negative regulation was through modulation of the micro-RNA miR34b-3p. Pharmacological inhibition of GPR55 via CBD in various pancreatic cell lines, inhibited anchorage-dependent growth. Treatment with CID16020046 (CID), an antagonist of GPR55, revealed similar results in AsPC- 1 and HPFA-II and cell cycle arrest at the $\mathrm{G}_{1}-\mathrm{S}$ phase in PANC-1 and HPFA-II in a dose-dependent manner. Cyclin D1, activation of tumour-suppressor protein (RB) was also reduced in CBD treatment and an inhibition of MEK/ ERK and ERK-dependent pathways was also observed. The study demonstrates a novel pathway by which gemcitabine may be potentiating anticancer effects through inhibiting GPR55 via CBD antagonization (Ferro et al. 2018).

\section{In vivo}

Administration of $\Delta^{9}-\mathrm{THC}$ at $15 \mathrm{mg} / \mathrm{kg} /$ day into a xenograft model of MIA PaCa-2 pancreatic tumour growth showed a reduction in the tumour burden (Carracedo et al. 2006). A synthetic cannabinoid, WIN55, 212-2 was found to increase the expression of downstream targets of the ER stressrelated pathway involved in apoptosis in pancreatic cancer in comparison to healthy controls, demonstrating apoptotic 
Table 1 Pre-clinical in vitro studies encompassing various cannabinoids in cancer models

\begin{tabular}{|c|c|c|c|c|c|}
\hline & Cancer Cell line & Cannabinoid (s) & $\begin{array}{l}\text { Inhibitory con- } \\
\text { centrations }\end{array}$ & In vitro actions & References \\
\hline \multirow[t]{2}{*}{ PDAC } & $\begin{array}{l}\text { MIA PaCa2, PANC-1, } \\
\text { Capan-2, BxPC-3 }\end{array}$ & $\begin{array}{l}\Delta^{9}-\mathrm{THC}, \mathrm{SR} 141716, \\
\text { SR144528 }\end{array}$ & $0-5 \mu \mathrm{M}$ & $\begin{array}{l}\text { Apoptosis via } \mathrm{CB}_{2} \text { and } \\
\text { p8, ATF4 and TRIB3 } \\
\text { and caspase- } 3 \text { activa- } \\
\text { tion }\end{array}$ & Carracedo et al. (2006) \\
\hline & $\begin{array}{l}\text { AsPC-I, HPFA-II, } \\
\text { PANC-I, BxPC-3 }\end{array}$ & $\mathrm{CBD}$ & $0-10 \mu \mathrm{M}$ & $\begin{array}{l}\text { Antiproliferative effects } \\
\text { via GPR55 }\end{array}$ & Ferro et al. (2018) \\
\hline \multirow[t]{13}{*}{ BRAIN } & $\begin{array}{l}\text { Human Glioblastoma, } \\
\text { U373-MG }\end{array}$ & $\begin{array}{l}\Delta^{9} \text {-THC, AEA, } \\
\text { HU-210, WIN } \\
55,212-2\end{array}$ & $100 \mathrm{nM}-10 \mu \mathrm{M}$ & $\begin{array}{l}\text { Accelerated cell prolif- } \\
\text { eration via EGFR and } \\
\text { MMP }\end{array}$ & McAllister et al. (2011) \\
\hline & $\begin{array}{l}\text { Human Glioblastoma, } \\
\text { U878MG, U373MG }\end{array}$ & $\begin{array}{l}\text { CBD, SR141716, } \\
\text { SR144528 }\end{array}$ & $5-40 \mu \mathrm{M}$ & $\begin{array}{l}\text { Antiproliferative effects } \\
\text { correlated to induc- } \\
\text { tion of apoptosis }\end{array}$ & Singer et al. (2015) \\
\hline & $\begin{array}{l}\text { Human Glioblastoma } \\
\text { multiforme, } \\
\text { SF126, U87-MG, } \\
\text { U251, SF188, } \\
\text { U373-MG, Human } \\
\text { GBM cultures }\end{array}$ & $\begin{array}{c}\Delta^{9}-\mathrm{THC}, \mathrm{WIN} \\
55,212-2\end{array}$ & $0.1 \mathrm{nM}-2 \mu \mathrm{M}$ & $\begin{array}{l}\text { Antiproliferative effects } \\
\text { and increase of } \\
\text { apoptosis }\end{array}$ & Ellert-Miklaszewska et al. (2021) \\
\hline & Rat C6 glioma cells & $\begin{array}{l}\text { WIN 55,212-2, WIN } \\
55,212-3\end{array}$ & $1-30 \mu \mathrm{M}$ & $\begin{array}{l}\text { Cell viability reduc- } \\
\text { tion, morphological } \\
\text { changes to cells }\end{array}$ & Matas et al. (2007) \\
\hline & Rat C6 glioma cells & $\begin{array}{l}\Delta^{9}-\mathrm{THC}, \mathrm{CBD}, \mathrm{CBD}- \\
\text { A, CBG, CBC, } \\
\text { AM251, JWH-133, } \\
\text { AM630, SR141716A, } \\
\text { SR144528 }\end{array}$ & $0-50 \mu \mathrm{M}$ & $\begin{array}{l}\text { CBD most potent. } \\
\text { CBD, CBG and } \\
\text { CBD-A activated } \\
\text { TRPV1 }\end{array}$ & Ligresti et al. (2006) \\
\hline & $\begin{array}{l}\text { Murine Neuroblastoma, } \\
\text { N18TG2 }\end{array}$ & AEA & $1-5 \mu \mathrm{M}$ & $\begin{array}{l}\text { Apoptosis and decrease } \\
\text { in cleavage of } \\
\text { PARP-1 }\end{array}$ & Marcu et al. (2010) \\
\hline & $\begin{array}{l}\text { Human Astrocytoma, } \\
\text { U87MG }\end{array}$ & $\Delta^{9}-\mathrm{THC}, \mathrm{SR} 141716$ & $1-10 \mu \mathrm{M}$ & $\begin{array}{l}\text { Apoptosis and } \\
\text { autophagy via ER } \\
\text { stress }\end{array}$ & Salazar et al. (2009) \\
\hline & $\begin{array}{l}\text { Human Glioma cancer, } \\
\text { U251, SF126, U87 }\end{array}$ & $\Delta^{9}-\mathrm{THC}, \mathrm{CBD}$ & $0.1-10 \mu \mathrm{M}$ & $\begin{array}{l}\text { Inhibition of cell prolif- } \\
\text { eration, apoptosis }\end{array}$ & Qamri et al. (2009) \\
\hline & $\begin{array}{l}\text { Human Glioblastoma, } \\
\text { U87-MG, T98G }\end{array}$ & $\mathrm{CBD}$ & $0-20 \mu \mathrm{M}$ & $\begin{array}{l}\text { Decrease in cell inva- } \\
\text { sion via MMP-9, } \\
\text { TIMP-1, TIMP-4, } \\
\text { u-PA, PAI-1, VEGF }\end{array}$ & Solinas et al. (2013) \\
\hline & $\begin{array}{l}\text { Human Glioma, T98G, } \\
\text { U87MG, Murine } \\
\text { Glioma, GL261 }\end{array}$ & $\begin{array}{l}\mathrm{CBD}, \Delta^{9}-\mathrm{THC} \text { (Pure } \\
\text { and BDS) }\end{array}$ & $0-20 \mu \mathrm{M}$ & $\begin{array}{l}\text { Increase in radiosensi- } \\
\text { tivity associated with } \\
\text { increase in apoptosis } \\
\text { and autophagy }\end{array}$ & Scott et al. (2014) \\
\hline & $\begin{array}{l}\text { Human Glioblastoma, } \\
\text { U251, 3832, } 387 \\
\text { Primary glioma stem } \\
\text { cells (GSC) lines }\end{array}$ & $\mathrm{CBD}$ & $0-5 \mu \mathrm{M}$ & $\begin{array}{l}\text { Activation of p-p38 } \\
\text { pathway, downregula- } \\
\text { tion of key stem cell } \\
\text { regulators; Sox2, Id1 } \\
\text { and p-STAT3 }\end{array}$ & Singer et al. (2015) \\
\hline & $\begin{array}{l}\text { Human Neuroblastoma, } \\
\text { SK-N-SH, IMR-32, } \\
\text { NUB-6 and LAN-1 }\end{array}$ & $\Delta^{9}-\mathrm{THC}, \mathrm{CBD}$ & $0-50 \mu \mathrm{g} / \mathrm{mL}$ & $\begin{array}{l}\text { Cell viability reduction } \\
\text { and apoptosis }\end{array}$ & Fisher et al. (2016) \\
\hline & $\begin{array}{l}\text { Human Glioblastoma, } \\
\text { U87MG, Glioblas- } \\
\text { toma patient derived } \\
\text { stem cell like cells } \\
\text { (GIC) }\end{array}$ & $\Delta^{9}-\mathrm{THC}, \mathrm{CBD}$ & $0-5 \mu \mathrm{M}$ & $\begin{array}{l}\text { Very significant } \\
\text { reduction of the GIC } \\
\text { population, induction } \\
\text { of apoptosis }\end{array}$ & López-Valero et al. (2018) \\
\hline
\end{tabular}


Table 1 (continued)

\begin{tabular}{|c|c|c|c|c|c|}
\hline & Cancer Cell line & Cannabinoid (s) & $\begin{array}{l}\text { Inhibitory con- } \\
\text { centrations }\end{array}$ & In vitro actions & References \\
\hline & $\begin{array}{l}\text { Human Glioma cells, } \\
\text { U87MG (U87), A172, } \\
\text { SW1783, U373MG } \\
\text { (U373), T98G (T98), } \\
\text { SW1088, and LN405 }\end{array}$ & $\begin{array}{l}\Delta^{9}-\mathrm{THC}, \mathrm{CBD}, \\
\text { SR141716, SR144528 }\end{array}$ & $0.9-3 \mu \mathrm{mol} / \mathrm{L}$ & $\begin{array}{l}\text { Reduction in cell } \\
\text { viability and induc- } \\
\text { tion of apoptosis and } \\
\text { autophagy }\end{array}$ & Torres et al. (2011) \\
\hline & $\begin{array}{l}\text { Human Glioma } \\
\text { cells, GOS3, U87 } \\
\text { MG (U87), A172, } \\
\text { SW1783, U118 MG } \\
\text { (U118), U373 MG } \\
\text { (U373), T98G (T98), } \\
\text { SW1088, CCF- } \\
\text { STTG1 (CCF) and } \\
\text { LN405 }\end{array}$ & $\begin{array}{l}\Delta^{9} \text {-THC, SR141716, } \\
\text { SR144528 }\end{array}$ & $0-2.5 \mu \mathrm{M}$ & $\begin{array}{l}\text { Sensitive and resistance } \\
\text { cell line determined } \\
\text { via reduction in cell } \\
\text { viability } \\
\text { Increased Mdk } \\
\text { expression confers } \\
\text { resistance of glioma } \\
\text { cells to } \Delta^{9} \text {-THC } \\
\text { pro-autophagic and } \\
\text { antitumoural action }\end{array}$ & Lorente et al. (2011) \\
\hline \multirow[t]{7}{*}{ BREAST } & $\begin{array}{l}\text { Human Breast adeno- } \\
\text { carcinoma, MDA- } \\
\text { MB-231, MCF-7, } \\
\text { murine mammary } \\
\text { carcinoma, 4T1 }\end{array}$ & $\Delta^{9}$-THC & $0-20 \mu \mathrm{M}$ & $\begin{array}{l}\text { No decrease observed } \\
\text { in cell viability for } \\
\text { all cell lines and low } \\
\text { level of cannabinoid } \\
\text { receptors }\end{array}$ & McKallip et al. (2005) \\
\hline & $\begin{array}{l}\text { Human Breast adeno- } \\
\text { carcinoma, EVSA-T }\end{array}$ & $\Delta^{9}-\mathrm{THC}$ & 3 and $5 \mu \mathrm{M}$ & $\begin{array}{l}\text { Antiproliferative effects } \\
\text { rely on JunD activity } \\
\text { and participation } \\
\text { of p8 }\end{array}$ & Caffarel et al. (2008) \\
\hline & $\begin{array}{l}\text { Human Breast adeno- } \\
\text { carcinoma, MDA- } \\
\text { MB-231, T47D, } \\
\text { murine breast cancer, } \\
\text { TSAE-1 }\end{array}$ & $\begin{array}{l}\text { Met-F-AEA, } \\
\text { SR141716A }\end{array}$ & $2.5-20 \mu \mathrm{M}$ & $\begin{array}{l}\text { Reduction in cell } \\
\text { viability in dose- } \\
\text { dependent manner } \\
\text { and decrease of tyros- } \\
\text { ine phosphorylation } \\
\text { of FAK and Src }\end{array}$ & Santoro et al. (2009) \\
\hline & $\begin{array}{l}\text { Human Breast adeno- } \\
\text { carcinoma, MDA- } \\
\text { MB-231, T47D, } \\
\text { MCF-7 }\end{array}$ & SR141716 & $0.1-1 \mu \mathrm{M}$ & $\begin{array}{l}\text { Cell cycle arrest, } \\
\text { decreased expression } \\
\text { of cyclins D and E } \\
\text { Antiproliferative effect } \\
\text { requires lipid raft/ } \\
\text { caveolae integrity to } \\
\text { occur }\end{array}$ & Sarnataro et al. (2005) \\
\hline & $\begin{array}{l}\text { Human Breast adeno- } \\
\text { carcinoma, EVSA-T, } \\
\text { MDA-MB-231, } \\
\text { MDA-MB-468, } \\
\text { SKBR3, MCF-7, } \\
\text { T-47D }\end{array}$ & $\begin{array}{l}\Delta^{9} \text {-THC, SR141716, } \\
\text { SR144528 }\end{array}$ & $1-12 \mu \mathrm{mol} / \mathrm{L}$ & $\begin{array}{l}\text { Reduction in cell pro- } \\
\text { liferation via the } \mathrm{CB}_{2} \\
\text { receptor, cell cycle } \\
\text { arrest, induction of } \\
\text { apoptosis }\end{array}$ & Caffarel et al. (2006) \\
\hline & $\begin{array}{c}\text { Human Breast adeno- } \\
\text { carcinoma, MDA- } \\
\text { MB-231, MCF-7 }\end{array}$ & $\begin{array}{l}\Delta^{9}-\mathrm{THC}, \mathrm{CBD}, \mathrm{CBG}, \\
\text { CBC, AM251, } \\
\text { JWH-133, AM630, } \\
\text { SR141716A, } \\
\text { SR144528 }\end{array}$ & $0-50 \mu \mathrm{M}$ & $\begin{array}{l}\text { CBD apoptotic effect } \\
\text { via activation of the } \\
\mathrm{CB}_{2} \text { receptor and } \\
\text { TRPV1 }\end{array}$ & Ligresti et al. (2006) \\
\hline & $\begin{array}{l}\text { Human Breast } \\
\text { adenocarcinoma, } \\
\text { MDA-MB-231, } \\
\text { MDA-MB-231-Luc, } \\
\text { MDA-MB-468 }\end{array}$ & $\begin{array}{l}\text { WIN 55,212-2, } \\
\text { JWH-133, AM251, } \\
\text { SR144528 }\end{array}$ & $0-10 \mu \mathrm{M}$ & $\begin{array}{l}\text { All cell lines express } \\
\text { both } \mathrm{CB}_{1} \text { and } \mathrm{CB}_{2} \\
\text { receptors } \\
\text { Inhibition of cell prolif- } \\
\text { eration and migration } \\
\text { via COX-2 signalling } \\
\text { and apoptosis }\end{array}$ & Hirao-Suzuki et al. (2020) \\
\hline
\end{tabular}


Table 1 (continued)

Cancer Cell line Cannabinoid (s) $\quad \begin{aligned} & \text { Inhibitory con- } \\ & \text { centrations }\end{aligned} \quad$ In vitro actions References

\begin{tabular}{|c|c|c|c|c|c|}
\hline & $\begin{array}{l}\text { Human Breast adeno- } \\
\text { carcinoma, MDA- } \\
\text { MB231 } \\
\text { Murine mammary } \\
\text { carcinoma, 4T1.2 }\end{array}$ & $\mathrm{CBD}$ & $1.5 \mu \mathrm{M}$ & $\begin{array}{l}\text { Inhibition of cell prolif- } \\
\text { eration and invasion } \\
\text { through modulation } \\
\text { of ERK and ROS, } \\
\text { downregulation of } \\
\text { Id-1 expression and } \\
\text { upregulation of Id-2 }\end{array}$ & Nallathambi et al. (2018) \\
\hline & $\begin{array}{l}\text { Human Breast adeno- } \\
\text { carcinoma, MDA- } \\
\text { MB-231, SKBR3, } \\
\text { MCF-7, ZR-75-1 }\end{array}$ & $\begin{array}{l}\text { CBD, AM251, AM630, } \\
\text { Capazepine }\end{array}$ & $0-10 \mu \mathrm{M}$ & $\begin{array}{l}\text { Decrease in cell } \\
\text { viability, autophagy } \\
\text { and apoptosis via ER } \\
\text { stress, inhibition of } \\
\text { Akt, mTOR signal- } \\
\text { ling }\end{array}$ & Lin et al. (2019) \\
\hline & $\begin{array}{l}\text { Human Breast adeno- } \\
\text { carcinoma, SUM159, } \\
\text { MDA-MB-231-SCP2, } \\
\text { MVT-1, murine } \\
\text { mammary carcinoma, } \\
\text { 4T1.2 }\end{array}$ & $\mathrm{CBD}$ & $3-15 \mu \mathrm{M}$ & $\begin{array}{l}\text { Cell proliferation } \\
\text { decreased, inhibi- } \\
\text { tion of the epidermal } \\
\text { growth factor (EGF)- } \\
\text { induced cell prolifera- } \\
\text { tion, migration, and } \\
\text { invasion }\end{array}$ & Grimaldi et al. (2006) \\
\hline & $\begin{array}{l}\text { Human Breast adeno- } \\
\text { carcinoma, MCF-7, } \\
\text { Murine mammary } \\
\text { carcinoma, 4T1 }\end{array}$ & $\begin{array}{l}\text { JWH-015, SR141716, } \\
\text { SR144528 }\end{array}$ & $0-10 \mu \mathrm{M}$ & $\begin{array}{l}\text { Decrease in cell } \\
\text { viability, apoptosis } \\
\text { and reduced ERK1/2 } \\
\text { levels, effects were } \\
\text { dependent in a } \\
\text { non-Goi -mediated, } \\
\text { calcium-dependency }\end{array}$ & McAllister et al. (2011) \\
\hline & $\begin{array}{l}\text { Human Breast adeno- } \\
\text { carcinoma, MDA- } \\
\text { MB-231 }\end{array}$ & AEA, AM251 & $0-0.5 \mu \mathrm{M}$ & $\begin{array}{l}\text { Reduction in } \mathrm{CD} 44^{+} / \\
\mathrm{CD} 24^{-/ \text {low }} / \mathrm{ESA}^{+} \text {can- } \\
\text { cer stem cell }(\mathrm{CSC}) \\
\text { invasiveness }\end{array}$ & Mohammadpour et al. (2017) \\
\hline & $\begin{array}{l}\text { Human Breast adeno- } \\
\text { carcinoma, MDA- } \\
\text { MB-231 }\end{array}$ & $\begin{array}{l}\text { CBDA, GSK0660, } \\
\text { GW501516, ST-247 }\end{array}$ & $1-50 \mu \mathrm{M}$ & $\begin{array}{l}\text { CBDA inhibits } \\
\text { PPAR } \beta / \delta \text { mediated } \\
\text { transcriptional activa- } \\
\text { tion and AP-1 }\end{array}$ & Gazzerro et al. (2010) \\
\hline & $\begin{array}{l}\text { Human Breast Cancer, } \\
\text { MDA-MB-231, } \\
\text { MCF-7 }\end{array}$ & $\mathrm{CBD}$ & $1-50 \mu \mathrm{M}$ & $\begin{array}{l}\text { Co-administration of } \\
\mathrm{CBD}_{\text {sol }} \text { and paclitaxel } \\
\text { or docetaxel showed a } \\
\text { synergistic effect }\end{array}$ & Fraguas-Sánchez et al. (2020) \\
\hline \multirow[t]{5}{*}{$\begin{array}{l}\text { GASTROIN- } \\
\text { TESTINAL }\end{array}$} & $\begin{array}{l}\text { Human Colon cancer, } \\
\text { DLD-1, CaCo-2, } \\
\text { SW620 }\end{array}$ & SR141716 & $0.1-20 \mu \mathrm{M}$ & $\begin{array}{l}\text { Reduction in cell prolif- } \\
\text { eration and cell cycle } \\
\text { arrest }\end{array}$ & Aviello et al. (2012) \\
\hline & $\begin{array}{l}\text { Human Colon adeno- } \\
\text { carcinoma, Caco-2, } \\
\text { HCT } 116\end{array}$ & $\begin{array}{l}\text { CBG, AM251, AM630, } \\
\text { AMTB (TRPM8 } \\
\text { antagonist), CBD, } \\
\text { CBDV, CBC }\end{array}$ & $1-50 \mu \mathrm{M}$ & $\begin{array}{l}\text { Apoptosis, increase } \\
\text { in ROS production } \\
\text { and upregulation of } \\
\text { CHOP expression }\end{array}$ & Borelli et al. (2014) \\
\hline & $\begin{array}{l}\text { Human Colorectal } \\
\text { carcinoma, DLD-1, } \\
\text { HCT116 }\end{array}$ & $\begin{array}{l}\text { CBD BS (botanical } \\
\text { substance), CBD, } \\
\text { AM630, SR141716, } \\
\text { SR144528 }\end{array}$ & $0.3-5 \mu \mathrm{M}$ & $\begin{array}{l}\text { Antiproliferative } \\
\text { effects, no effect on } \\
\text { cell viability }\end{array}$ & Romano et al. (2014) \\
\hline & $\begin{array}{l}\text { Human Colorectal } \\
\text { cancer, Caco-2 }\end{array}$ & CBD & $0.1-10 \mu \mathrm{M}$ & $\begin{array}{l}\text { PhysO }_{2} \text { cells signifi- } \\
\text { cantly more sensitive } \\
\text { to antiproliferative } \\
\text { effects of CBD than } \\
\text { AtmosO }_{2}\end{array}$ & Macpherson et al. 2014 \\
\hline & $\begin{array}{l}\text { Human Colon cancer, } \\
\text { DLD-1 }\end{array}$ & SR141716 & $0.1-10 \mu \mathrm{M}$ & $\begin{array}{l}\text { Inhibition of cell } \\
\text { proliferation at higher } \\
\text { concentrations }\end{array}$ & Gazzerro et al. (2010) \\
\hline
\end{tabular}


Table 1 (continued)

\begin{tabular}{|c|c|c|c|c|c|}
\hline & Cancer Cell line & Cannabinoid (s) & $\begin{array}{l}\text { Inhibitory con- } \\
\text { centrations }\end{array}$ & In vitro actions & References \\
\hline & $\begin{array}{l}\text { Human Colon cancer, } \\
\text { SW480 }\end{array}$ & CBD, WIN 55,212-2 & $0-15 \mu \mathrm{M}$ & $\begin{array}{l}\text { Induction of cellular } \\
\text { ACPP, DUSP1, } \\
\text { DUSP10, cleavage of } \\
\text { PARP, Apoptosis }\end{array}$ & De Petrocellis et al. (2013) \\
\hline & $\begin{array}{l}\text { Human colorectal } \\
\text { carcinoma, Caco-2, } \\
\text { HCT116 }\end{array}$ & $\begin{array}{l}\text { CBD, SR141716, } \\
\text { AM251, SR144528, } \\
\text { AM630, GW9662, } \\
\text { Capsazepine }\end{array}$ & $0.01-10 \mu \mathrm{M}$ & $\begin{array}{l}\text { Reduction in cell } \\
\text { viability and expres- } \\
\text { sion of phospho-Akt }\end{array}$ & Aviello et al. (2012) \\
\hline & $\begin{array}{l}\text { Human Colon cancer, } \\
\text { HCT116, SW48 }\end{array}$ & SR141716 & $0-20 \mu \mathrm{M}$ & $\begin{array}{l}\text { Inhibition of cell } \\
\text { growth, increase of } \\
\text { caspase- } 3 \text { and cleav- } \\
\text { age of PARP }\end{array}$ & Proto et al. (2017) \\
\hline & $\begin{array}{l}\text { Human Colon cancer, } \\
\text { HCT116 and DLD-1 } \\
\text { Organoids }\end{array}$ & SR141716 & $0.1-20 \mu \mathrm{M}$ & $\begin{array}{l}\text { Reduction in colon } \\
\text { CSCs proliferation } \\
\text { and tumour differenti- } \\
\text { ated cells }\end{array}$ & Fiore et al. (2018) \\
\hline & $\begin{array}{l}\text { Human Hepatocellular } \\
\text { carcinoma, HepG2, } \\
\text { HuH-7 }\end{array}$ & $\begin{array}{l}\Delta^{9} \text {-THC, JWH-015, } \\
\text { SR141716, SR144528 }\end{array}$ & $1-8 \mu \mathrm{M}$ & $\begin{array}{l}\text { Reduction in cell } \\
\text { viability occurred } \\
\text { via } \mathrm{CB}_{2} \text { receptor and } \\
\text { autophagy }\end{array}$ & Vara et al. (2011) \\
\hline & $\begin{array}{l}\text { Human Hepatocellular } \\
\text { carcinoma, BEL7402 }\end{array}$ & $\begin{array}{l}\text { WIN 55, 212-2, } \\
\text { AM630, JWH-015 }\end{array}$ & 0,5 or $10 \mu \mathrm{M}$ & $\begin{array}{l}\mathrm{CB}_{2} \text { mediated down- } \\
\text { regulation of phos- } \\
\text { phorylated ERK1/2 }\end{array}$ & Xu et al. (2016) \\
\hline & $\begin{array}{l}\text { Human Gastric adeno- } \\
\text { carcinoma, AGS }\end{array}$ & $\begin{array}{l}\text { AEA, Meth-AEA (R- } \\
(+)), \text { CP 55,940 }\end{array}$ & $0.5-5 \mu \mathrm{M}$ & $\begin{array}{l}\text { Concentration-depend- } \\
\text { ent effects in cell } \\
\text { morphology and loss } \\
\text { changes }\end{array}$ & Ortega et al. (2016) \\
\hline & $\begin{array}{l}\text { Gastric cancer, } \\
\text { SGC7901, AGS cells }\end{array}$ & WIN 55,212-2 & $5 \mu \mathrm{M}$ & $\begin{array}{l}\text { Inhibition of cell } \\
\text { migration, invasion } \\
\text { and EMT }\end{array}$ & Xian et al. (2016) \\
\hline \multirow[t]{6}{*}{ PROSTATE } & $\begin{array}{l}\text { Human Prostate Can- } \\
\text { cer, PC-3 }\end{array}$ & $\begin{array}{c}\Delta^{9}-\mathrm{THC}, \text { AM251, } \\
\text { WIN55,212-2 }\end{array}$ & $0.5-10 \mu \mathrm{M}$ & $\begin{array}{l}\text { Reduction in cell via- } \\
\text { bility and apoptosis }\end{array}$ & Ruiz et al. (1999) \\
\hline & $\begin{array}{l}\text { Human Prostate Can- } \\
\text { cer, LNCaP, DU145, } \\
\text { PC-3 }\end{array}$ & AEA & $1-10 \mu \mathrm{M}$ & $\begin{array}{l}\text { Decrease of EGFR } \\
\text { levels in all cell lines } \\
\text { via } \mathrm{CB}_{1} \text { leading to an } \\
\text { inhibition of EGF- } \\
\text { stimulated growth }\end{array}$ & Mimeault et al. (2003) \\
\hline & $\begin{array}{l}\text { Human Prostate Can- } \\
\text { cer, LNCaP }\end{array}$ & $\begin{array}{l}\text { MET-AEA, HU-210, } \\
\text { JWH-015, SR141716, } \\
\text { SR144528 }\end{array}$ & $0.05-5 \mu \mathrm{M}$ & $\begin{array}{l}\text { Involvement of PI3K } \\
\text { pathway and modi- } \\
\text { fication of androgen } \\
\text { receptor expression }\end{array}$ & Sanchez et al. (2003) \\
\hline & $\begin{array}{l}\text { Human Prostate carci- } \\
\text { noma, LNCaP, PC3 }\end{array}$ & $\begin{array}{l}\text { WIN-55,212-2, } \\
\text { SR141716, SR144528 }\end{array}$ & $1-30 \mu \mathrm{M}$ & $\begin{array}{l}\text { Induction in p27/KIP1 } \\
\text { and downregulation } \\
\text { in cyclin and CDK } \\
\text { levels. Upregula- } \\
\text { tion of ERK1/2 and } \\
\text { inhibition of PI3k/Akt } \\
\text { pathways }\end{array}$ & Sarfaraz et al. (2006) \\
\hline & $\begin{array}{l}\text { Human Prostate cancer, } \\
\text { LNCaP, 22RV1, } \\
\text { DU-145, PC-3 }\end{array}$ & $\begin{array}{l}\text { CBC, CBD, CBG, } \\
\text { CBN, CBDA, CBGA, } \\
\text { CBDV, CBGV, THC, } \\
\text { THCA, THCV, } \\
\text { THCVA }\end{array}$ & $1-10 \mu \mathrm{M}$ & $\begin{array}{l}\text { Decrease in cell viabil- } \\
\text { ity and activation of } \\
\text { the intrinsic apoptotic } \\
\text { pathway }\end{array}$ & De Petrocellis et al. (2013) \\
\hline & $\begin{array}{l}\text { Human Prostate adeno- } \\
\text { carcinoma, PC-3, Pri- } \\
\text { mary cultures; BPH, } \\
\text { LGG, HGG, PrC }\end{array}$ & $\begin{array}{l}\text { AEA, 2-AG, Methanan- } \\
\text { damide (AM-356), } \\
\text { SR141716 }\end{array}$ & $\begin{array}{c}2.5,5 \text { and } \\
10 \mu \mathrm{M}\end{array}$ & $\begin{array}{l}\text { Cell cycle arrest and } \\
\text { induction of apoptosis }\end{array}$ & Orellana-Serradell et al. (2015) \\
\hline
\end{tabular}


Table 1 (continued)

Cancer Cell line Cannabinoid (s) Inhibitory con- $\quad$ In vitro actions $\quad$ References
centrations

\begin{tabular}{|c|c|c|c|c|c|}
\hline & $\begin{array}{l}\text { Human Prostate cancer, } \\
\text { LNCaP, PC-3 }\end{array}$ & $\begin{array}{l}\text { WIN 55,212-2, } \\
\text { SR141716, SR144528 }\end{array}$ & $0-10 \mu \mathrm{M}$ & $\begin{array}{l}\text { WIN prevents neuroen- } \\
\text { docrine differentia- } \\
\text { tion by downregula- } \\
\text { tion of PI3K/Akt/ } \\
\text { mTOR signalling }\end{array}$ & Morell et al. (2016) \\
\hline \multirow[t]{5}{*}{ LUNG } & $\begin{array}{l}\text { Human Lung carci- } \\
\text { noma, NCI-H292 }\end{array}$ & $\begin{array}{l}\Delta^{9} \text {-THC, AEA, } \\
\text { HU-210, WIN } \\
55,212-2\end{array}$ & $0.1-10 \mu \mathrm{M}$ & $\begin{array}{l}\text { Increase in cell prolif- } \\
\text { eration dependent on } \\
\text { EGFR and MMP }\end{array}$ & Hart et al. (2004) \\
\hline & $\begin{array}{l}\text { Human NSCLC, } \\
\text { EGF-induced, A549, } \\
\text { SW-1573 }\end{array}$ & $\Delta^{9}$-THC & $1-20 \mu \mathrm{M}$ & $\begin{array}{l}\text { Apoptosis and inhibi- } \\
\text { tion of proliferation } \\
\text { via EGF-induced } \\
\text { phosphorylation of } \\
\text { ERK1/2, JNK1/1 and } \\
\text { Akt }\end{array}$ & Preet et al. (2008) \\
\hline & $\begin{array}{l}\text { Human Lung adenocar- } \\
\text { cinoma, A549, H460 } \\
\text { Primary non-small-cell } \\
\text { lung carcinoma cells }\end{array}$ & $\begin{array}{l}\text { CBD, AM251, AM630, } \\
\text { Capsazepine, NS-398 }\end{array}$ & $0-10 \mu \mathrm{M}$ & $\begin{array}{l}\text { Decrease in the } \\
\text { viability of the cells } \\
\text { and upregulation of } \\
\text { COX-2 and PPAR- } \gamma \\
\text { expression, PGE } \\
\text { PGD }_{2} \text {, and } 15 \mathrm{~d}^{-} \mathrm{PGJ}_{2}\end{array}$ & Ramer et al. (2013) \\
\hline & $\begin{array}{l}\text { Human NSCLC; A549 } \\
\text { (epithelial), CALU1 } \\
\text { (mesenchymal) }\end{array}$ & JWH-015, SR144528 & $0-5 \mu \mathrm{M}$ & $\begin{array}{l}\text { Decreased migratory } \\
\text { and invasive abilities } \\
\text { via reduction in FAK, } \\
\text { VCAM1, MMP2 }\end{array}$ & Ravi et al. (2016) \\
\hline & $\begin{array}{l}\text { Human Lung cancer; } \\
\text { A549 }\end{array}$ & WIN 55,212-2 & $5-20 \mu \mathrm{M}$ & $\begin{array}{l}\text { Decline in cell viability } \\
\text { due to apoptosis }\end{array}$ & Müller et al. (2017) \\
\hline \multirow[t]{4}{*}{ BLOOD } & $\begin{array}{l}\text { Human Leukaemia; } \\
\text { CEM (acute lympho- } \\
\text { blastic), HEL-92 } \\
\text { (erythroblastic), } \\
\text { HL60 (acute promye- } \\
\text { locytic), MOLT-4 } \\
\text { (acute lymphoblastic) } \\
\text { and PBMCs }\end{array}$ & $\Delta^{9}$-THC & $0-100 \mu \mathrm{M}$ & $\begin{array}{l}\text { Cell death via activa- } \\
\text { tion of MAPK }\end{array}$ & Powles et al. (2005) \\
\hline & $\begin{array}{l}\text { Human Leukaemia, } \\
\text { Jurkat, MOLT-4 and } \\
\text { murine lymphoma, } \\
\text { EL-4 }\end{array}$ & $\begin{array}{l}\text { CBD, SR141716A, } \\
\text { SR144528, CAPZ }\end{array}$ & $0-10 \mu \mathrm{M}$ & $\begin{array}{l}\text { Significant reduction } \\
\text { in cell viability and } \\
\text { apoptosis through the } \\
\mathrm{CB}_{2} \text { receptor }\end{array}$ & McKallip et al. (2006) \\
\hline & $\begin{array}{l}\text { Human Myeloma, } \\
\text { U266, U266-LR7, } \\
\text { RPMI, RPMI-LR5, } \\
\text { MM1.S, MM1.R }\end{array}$ & WIN 55,212-2 & $5-50 \mu \mathrm{M}$ & Apoptosis & Barbado et al. (2017) \\
\hline & $\begin{array}{l}\text { Human T acute lymph- } \\
\text { oblastic leukaemia, } \\
\text { Jurkat }\end{array}$ & CBD & $0.01-10 \mu \mathrm{M}$ & $\begin{array}{l}\text { Reduction in cell } \\
\text { viability and cell } \\
\text { cycle changes }\end{array}$ & Kalenderoglu et al. (2017) \\
\hline \multirow[t]{3}{*}{ SKIN } & $\begin{array}{l}\text { Melanoma, A375, } \\
\text { MelJuso and murine } \\
\text { melanoma, B16 }\end{array}$ & $\begin{array}{l}\Delta^{9}-\mathrm{THC}, \mathrm{WIN}- \\
55,212-2, \text { SR141716, } \\
\text { SR144528 }\end{array}$ & $0.5-1 \mu \mathrm{M}$ & $\begin{array}{l}\text { Reduction in cell } \\
\text { viability, angiogen- } \\
\text { esis, and metastasis } \\
\text { via CB receptors }\end{array}$ & Blázquez et al. (2006) \\
\hline & $\begin{array}{l}\text { Human Melanoma, } \\
\text { CHL-1, A375, SK- } \\
\text { MEL-28BD }\end{array}$ & $\Delta^{9}-\mathrm{THC}, \mathrm{CBD}$ & $0-10 \mu \mathrm{M}$ & $\begin{array}{l}\text { Decrease in cell } \\
\text { viability }\end{array}$ & Armstrong et al. (2015) \\
\hline & $\begin{array}{l}\text { Murine squamous, } \\
\text { non-melanoma skin } \\
\text { cancer; JWF2 }\end{array}$ & $\begin{array}{l}\text { AEA, AMG9810, } \\
\text { AM251, AM630 }\end{array}$ & 2.5- $40 \mu \mathrm{M}$ & $\begin{array}{l}\text { Reduction in cell } \\
\text { viability and apopto- } \\
\text { sis via ER stress }\end{array}$ & Soliman et al. (2016) \\
\hline
\end{tabular}


Table 1 (continued)

\begin{tabular}{|c|c|c|c|c|}
\hline Cancer Cell line & Cannabinoid (s) & $\begin{array}{l}\text { Inhibitory con- } \\
\text { centrations }\end{array}$ & In vitro actions & References \\
\hline $\begin{array}{l}\text { Human renal carci- } \\
\text { noma, 786-O, SMKT- } \\
\text { R2, SMKT-R3, Caki- } \\
\text { 2, RCC-6, 769-P, } \\
\text { Caki-1, ACHN }\end{array}$ & $\begin{array}{l}\text { WIN 55,212-2, JWH- } \\
\text { 133, SR141716A, } \\
\text { AM630 }\end{array}$ & $0-25 \mu \mathrm{M}$ & $\begin{array}{l}\text { Reduction in cell prolif- } \\
\text { eration and induction } \\
\text { of apoptosis }\end{array}$ & Khan et al. (2018) \\
\hline $\begin{array}{l}\text { Human ovarian cancer, } \\
\text { SKOV-3 }\end{array}$ & $\mathrm{CBD}$ & $10-50 \mu \mathrm{M}$ & $\begin{array}{l}\text { Inhibition of cell prolif- } \\
\text { eration }\end{array}$ & Fraguas-Sánchez et al. (2020) \\
\hline $\begin{array}{l}\text { Rat Adrenal Gland; } \\
\text { PC12 cells }\end{array}$ & DHA-DA, AEA & $0-80 \mu \mathrm{M}$ & $\begin{array}{l}\text { NOS activation, } \\
\text { increased } \mathrm{Ca}^{2+} \\
\text { signalling leading to } \\
\text { apoptosis via GPR55 } \\
\text { activation }\end{array}$ & Akimov et al. (2021) \\
\hline
\end{tabular}

MET-AEA (methanandamide, non-hydrolyzable analogue of AEA), AEA (anandamide), DHA-DA ( $N$-docosahexaenoyl dopamine), AM251 (CB antagonist), HU-210 ( $\mathrm{CB}_{1}$ agonist), JWH-015 ( $\mathrm{CB}_{2}$ agonist), JWH-133 ( $\mathrm{CB}_{2}$ agonist), WIN 55,212-2 (CB agonist$), ~ S R 141716 ~\left(C B_{1}\right.$ inverse agonist), SR144528 ( $\mathrm{CB}_{2}$ inverse agonist), N-oleoylethanolamine (NOE) (acidic ceramidase inhibitor), LY294002 (PI3K inhibitor), PD98059 (ERK inhibitor), PBMCs (peripheral blood mononuclear cells), AM630 ( CB $_{2}$ antagonist), GW9662 (PPAR- $\gamma$ antagonist), GSK066 (PPAR $\beta / \delta$ antagonist), GSK501516 (PPARס antagonist), AMG9810 (TRPV1 antagonist)

selectivity effect of cannabinoids to cancer cells (Carracedo et al. 2006).

The role of other cannabinoid receptors including GPR55 has been speculated to be involved in regulating many cancer types including pancreatic cancer. A study by Ferro et al. revealed genetic ablation of GPR55 in a KPC mouse model of pancreatic ductal adenocarcinoma (PDAC) significantly prolonged survival and KPC mice treated with CBD and gemcitabine as a combination treatment survived three times longer than control or gemcitabine single treatment (Ferro et al. 2018). Immunohistochemistry analysis of the tumours revealed CBD inhibition of GPR55 affected signalling pathways involved in gemcitabine resistance. CBD was able to counteract the effect of gemcitabine on ERK phosphorylation and downregulated the enzyme's ribonucleotide reductases 1 and 2 (RRM1/2), a marker for gemcitabine resistance (Ferro et al. 2018). In line with this, gemcitabine-treated tumours from KPC mice expressed high levels of RRM1 and reduced levels were observed in KPCG mice upon treatment with CBD (Ferro et al. 2018). The counteractions of $\mathrm{CBD}$ on gemcitabine only occurred when both drugs were administered together, suggesting synergistic effects of CBD on gemcitabine's mode of action in vivo (Ferro et al. 2018). Donadelli et al. also reported an enhanced effect with combination therapy. $\mathrm{CB}_{1}$ antagonist, Rimonabant, combined with gemcitabine reduced tumour growth when compared to single therapy in vivo (Donadelli et al. 2011). An increase in ROS and autophagy pathways were observed which may explain the synergistic effects they observed (Donadelli et al. 2011).

The translation of preclinical data to the clinic remains to be somewhat unclear as many factors in cannabinoids pharmacokinetics, bioactivity and efficacy remain undetermined
(Ladin et al. 2016; Millar et al. 2018). In addition, their low aqueous solubility and poor stability (sensitivity to light, temperature and oxidation) make developing effective formulations a problem (Fraguas-Sánchez et al. 2020). The route of cannabinoid administration remains uncertain as the oral bioavailability is very low and is subject to a significant first-pass effect in the body (Millar et al. 2018). Therefore, alternative routes of administration are required, although it has been reported that intratumour (IT) administration of low doses of cannabinoids has improved efficacy of the drug as well as survival (Ngwa et al. 2017, 2018; Yasmin-Karim et al. 2018). Successful administration has been reported when cannabinoids were combined with radiotherapy in treating pancreatic cancer (Yasmin-Karim et al. 2018).

A recent study has reported the use of CBD and $\Delta^{9}$-THC inhibited proliferation of pancreatic cancer and stellate cells. PDL-1 (a key target for immune checkpoint blockade) expression was reduced in mice tumours via the PAK1-dependent pathway (p-21 activated kinase 1) activated by Kirsten rat sarcoma (KRAS). Their findings suggest a novelty for the cannabinoids in which KRAS, an undruggable target expressed in many lethal cancers can be supressed through targeting PAK1 and the suppression of PDL-1 could be enhanced for immune checkpoint blockade therapy in pancreatic cancers (Yang et al. 2020).

\section{Brain cancer}

\section{In vitro}

Investigation into human glioma cell lines U87 and U373 administered with CBD led to a decrease in mitochondrial oxidative metabolism, cell viability and antiproliferative 
Table 2 Pre-clinical in vivo studies encompassing various cannabinoids in cancer models

\begin{tabular}{|c|c|c|c|c|}
\hline & In vivo model & Cannabinoid (s) & Observed changes & References \\
\hline \multirow[t]{2}{*}{ PDAC } & $\begin{array}{l}\text { Immunodeficient nude mice and } \\
\text { human PDAC cell lines } \\
\text { MIA PaCa-2, PANC-1, Capan-2, } \\
\text { BxPC-3 }\end{array}$ & $\begin{array}{l}\Delta^{9}-\mathrm{THC}, \mathrm{JWH}-133, \mathrm{WIN}- \\
55,212-2\end{array}$ & $\begin{array}{l}\text { Reduction in growth of tumour } \\
\text { and induction of apoptosis via } \\
\text { activation of the p8-ATF-4TRB3 } \\
\text { proapoptotic pathway }\end{array}$ & $\begin{array}{l}\text { Carracedo et al. } \\
\text { (2006) }\end{array}$ \\
\hline & $\begin{array}{l}\text { KPC PDAC mouse model (muta- } \\
\text { tions in KRAS, PanIN, TP53) } \\
\text { mice with homozygous deletion } \\
\text { of GPR55 created KPCG strain }\end{array}$ & $\mathrm{CBD}$ & $\begin{array}{l}\text { KPC mice treated with combination } \\
\text { of CBD and GEM survived longer } \\
\text { than vehicle or GEM alone }\end{array}$ & Ferro et al. (2018) \\
\hline \multirow[t]{8}{*}{ BRAIN } & $\begin{array}{l}\text { Athymic female CD-1 nude mice } \\
\text { and human glioma U87, U373 } \\
\text { cell lines }\end{array}$ & CBD, SR141716, SR144528 & $\begin{array}{l}\text { CBD significantly inhibited the } \\
\text { growth of tumours }\end{array}$ & Massi et al. (2004) \\
\hline & $\begin{array}{l}\text { Nude mice and human astrocy- } \\
\text { toma U87MG }\end{array}$ & $\Delta^{9}-\mathrm{THC}$ & Autophagy and apoptosis & Salazar et al. (2009) \\
\hline & $\begin{array}{l}\text { Female C57BL/6 and murine } \\
\text { glioma GL261 }\end{array}$ & $\begin{array}{l}\mathrm{CBD}, \Delta^{9}-\mathrm{THC} \text { (Pure and } \\
\mathrm{BDS} \text { ) }\end{array}$ & $\begin{array}{l}\text { Triple combination of CBD, } \Delta^{9}- \\
\text { THC and irradiation significantly } \\
\text { reduced tumour growth }\end{array}$ & Scott et al. (2004) \\
\hline & $\begin{array}{l}\text { Female Athymic (nu/nu) mice and } \\
\text { human glioblastoma U251 and } \\
\text { primary glioma stem cells } 3832 \text {, } \\
387\end{array}$ & CBD & $\begin{array}{l}\text { Increase in the survival rate of mice } \\
\text { bearing GSC xenografts }\end{array}$ & Singer et al. (2015) \\
\hline & $\begin{array}{l}\text { Immunodeficient (NOD/SCID) } \\
\text { mice and human neuroblastoma } \\
\text { SK-N-SH cell lines }\end{array}$ & $\Delta^{9}-\mathrm{THC}, \mathrm{CBD}$ & $\begin{array}{l}\text { Reduction in the growth of tumours } \\
\text { and increase in activated caspase- } 3\end{array}$ & Fisher et al. (2016) \\
\hline & $\begin{array}{l}\text { Nude mice and human glioblas- } \\
\text { toma U87MG cell line }\end{array}$ & $\Delta^{9}-\mathrm{THC}, \mathrm{CBD}$ & Reduction in tumour growth & $\begin{array}{l}\text { López-Valero et al. } \\
\text { (2018) }\end{array}$ \\
\hline & Nude mice and U87, T98 cell lines & $\Delta^{9}-\mathrm{THC}, \mathrm{CBD}$ & $\begin{array}{l}\text { Reduction in tumour growth more } \\
\text { significant when combined with } \\
\text { temozolomide (TMZ) }\end{array}$ & Torres et al. (2011) \\
\hline & Nude mice and U87, T98 cell lines & $\begin{array}{l}\Delta^{9} \text {-THC, SR141716, } \\
\text { SR144528 }\end{array}$ & $\begin{array}{l}\text { Silencing of Mdk sensitizes cannabi- } \\
\text { noid resistant tumours to } \Delta^{9} \text {-THC } \\
\text { anticancer action, although no } \\
\text { effect on tumour growth }\end{array}$ & Lorente et al. (2011) \\
\hline \multirow[t]{8}{*}{ BREAST } & $\begin{array}{l}\text { Female adult BALB/c and SCID- } \\
\text { NOD mice and murine mam- } \\
\text { mary carcinoma } 4 \mathrm{~T} 1\end{array}$ & $\Delta^{9}-\mathrm{THC}$ & $\begin{array}{l}\text { Increase in tumour growth and } \\
\text { metastasis due to inhibition of spe- } \\
\text { cific antitumor immune response }\end{array}$ & McKallip et al. (2005) \\
\hline & $\begin{array}{l}\text { Male athymic mice and human } \\
\text { breast adenocarcinoma, } \\
\text { MDA-MB-231, MCF-7 }\end{array}$ & $\begin{array}{l}\Delta^{9}-\mathrm{THC}, \mathrm{CBD}, \mathrm{CBG}, \mathrm{CBC}, \\
\text { SR141716A, SR144528 }\end{array}$ & $\begin{array}{l}\text { CBD inhibited tumour growth and } \\
\text { reduced lung metastasis }\end{array}$ & Ligresti et al. (2006) \\
\hline & $\begin{array}{l}\text { Male C57BL/6 N mice and murine } \\
\text { mammary carcinoma, TSAE-1 }\end{array}$ & Met-F-AEA, SR141716A & $\begin{array}{l}\text { Reduction of metastatic nodes in } \\
\text { mice }\end{array}$ & Santoro et al. (2009) \\
\hline & $\begin{array}{l}\text { Female adult CD1 nude mice and } \\
\text { human breast adenocarcinoma, } \\
\text { MDA-MB-231 }\end{array}$ & SR141716 & Reduction in tumour volume & Sarnataro et al. (2005) \\
\hline & $\begin{array}{l}\text { Severe combined immunodeficient } \\
\text { CB-17 mice and human breast } \\
\text { adenocarcinoma, MDA-MB-231/ } \\
\text { luc/486 }\end{array}$ & WIN 55,212-2, JWH-133 & $\begin{array}{l}40-50 \% \text { reduction in tumour burden, } \\
65-80 \% \text { reduction in lung metas- } \\
\text { tases }\end{array}$ & $\begin{array}{l}\text { Hirao-Suzuki et al. } \\
\text { (2020) }\end{array}$ \\
\hline & $\begin{array}{l}\text { Female BALB/cfC } 3 \mathrm{H} \text { mice and } \\
\text { murine mammary carcinoma } \\
4 \mathrm{~T} 1\end{array}$ & $\mathrm{CBD}$ & $\begin{array}{l}\text { Significant reduction of primary } \\
\text { tumour mass and size and lung } \\
\text { metastatic foci }\end{array}$ & $\begin{array}{l}\text { Shrivastava et al. } \\
\text { (2011) }\end{array}$ \\
\hline & $\begin{array}{l}\text { Female BALB/c and FVB mice } \\
\text { and murine mammary carcinoma } \\
4 \mathrm{~T} 1\end{array}$ & CBD & $\begin{array}{l}\text { Reduction in the growth of tumours } \\
\text { and vascularity and inhibition of } \\
\text { lung metastasis }\end{array}$ & Grimaldi et al. (2006) \\
\hline & $\begin{array}{l}\text { Female } \mathrm{BALB} / \mathrm{cfC} 3 \mathrm{H} \text { mice and } \\
\text { murine mammary carcinoma } \\
\text { 4T1 }\end{array}$ & JWH-015 & $\begin{array}{l}\text { Significant reduction in primary } \\
\text { tumour burden and metastasis }\end{array}$ & $\begin{array}{l}\text { McAllister et al. } \\
\text { (2011) }\end{array}$ \\
\hline
\end{tabular}


Table 2 (continued)

\begin{tabular}{|c|c|c|c|c|}
\hline & In vivo model & Cannabinoid (s) & Observed changes & References \\
\hline \multirow[t]{6}{*}{$\begin{array}{l}\text { COLO- } \\
\text { RECTAL }\end{array}$} & $\begin{array}{l}\text { Male C57BL/6 N mice, chemically } \\
\text { induced colon cancer }\end{array}$ & SR141716 & $\begin{array}{l}\text { Inhibition of tumour growth and } \\
\text { reduction in ACF induced colon } \\
\text { cancer }\end{array}$ & Santoro et al. (2009) \\
\hline & $\begin{array}{l}\text { Male athymic (nu/nu) mice and } \\
\text { human hepatocellular carcinoma, } \\
\text { HepG2 and HuH-7 }\end{array}$ & $\begin{array}{l}\Delta^{9} \text {-THC, JWH-015, } \\
\text { SR-141716, SR144258 }\end{array}$ & $\begin{array}{l}\text { Reduction of tumour growth and } \\
\text { ascites }\end{array}$ & Vara et al. (2011) \\
\hline & $\begin{array}{l}\text { Male ICR mice and human colo- } \\
\text { rectal carcinoma, Caco- } 2 \text { and } \\
\text { HCT116 }\end{array}$ & $\mathrm{CBD}$ & $\begin{array}{l}\text { Reduction in ACF, polyps and } \\
\text { tumour formation in AOM model }\end{array}$ & Aviello et al. (2012) \\
\hline & $\begin{array}{l}\text { Male ICR and athymic nude } \\
\text { female mice and human colon } \\
\text { adenocarcinoma, Caco-2 and } \\
\text { HCT } 116\end{array}$ & CBG, AM-251, AM-630 & CBG inhibited colon cancer growth & Borelli et al. (2014) \\
\hline & $\begin{array}{l}\text { Male ICR and athymic nude mice } \\
\text { and human colorectal carcinoma, } \\
\text { DLD-1 and HCT } 116\end{array}$ & $\mathrm{CBD}, \mathrm{CBD} \mathrm{BS}$ & $\begin{array}{l}\text { Reduction of AOM induced preneo- } \\
\text { plastic lesions and overall tumour } \\
\text { growth }\end{array}$ & Romano et al. (2014) \\
\hline & $\begin{array}{l}\text { Female SCID mice and human } \\
\text { colon cancer, HCT116 and } \\
\text { SW48 }\end{array}$ & SR141716 & $\begin{array}{l}\text { Significant reduction in tumour } \\
\text { growth } \\
\text { Destabilization of the nuclear locali- } \\
\text { zation of } \beta \text {-Catenin }\end{array}$ & Proto et al. (2017) \\
\hline \multirow[t]{2}{*}{$\begin{array}{l}\text { PROS- } \\
\text { TATE }\end{array}$} & $\begin{array}{l}\text { Male MR-1 nude mice and pros- } \\
\text { tate carcinoma, LNCaP, 22RV1, } \\
\text { DU-145 and PC-3 }\end{array}$ & $\begin{array}{l}\text { CBC, CBD, CBG, CBN, } \\
\text { CBDA, CBGA, CBDV, } \\
\text { CBGV, THC, THCA, } \\
\text { THCV, THCVA BDS }\end{array}$ & $\begin{array}{l}\text { Reduction of the LNCaP xenograft } \\
\text { growth }\end{array}$ & $\begin{array}{l}\text { De Petrocellis et al. } \\
\text { (2013) }\end{array}$ \\
\hline & $\begin{array}{l}\text { Male athymic nude-FOxn1 (nu/nu) } \\
\text { mice and human prostate cancer } \\
\text { LNCaP }\end{array}$ & $\begin{array}{l}\text { WIN 55,212-2, SR-141716, } \\
\text { SR-144528 }\end{array}$ & $\begin{array}{l}\text { Reduction in rate of growth and size } \\
\text { of tumours }\end{array}$ & Morell et al. (2016) \\
\hline \multirow[t]{4}{*}{ LUNG } & $\begin{array}{l}\text { Male C57BL/6 }\left(\mathrm{H}-2^{\mathrm{b}}\right) \text { and } \\
\text { BALB/c mice }(\mathrm{H}-2 \mathrm{~d}) \text { and } \\
\text { murine Lewis/alveolar cell lung } \\
\text { carcinoma }\end{array}$ & $\begin{array}{l}\Delta^{9} \text {-THC, SR141716, } \\
\text { SR144528 }\end{array}$ & $\begin{array}{l}\text { Increase in the growth of the } 3 \mathrm{LL} \\
\text { and } \mathrm{L} 1 \mathrm{C} 2 \text { tumors in vivo }\end{array}$ & Zhu et al. (2000) \\
\hline & $\begin{array}{l}\text { SCID CB-17 mice and human } \\
\text { NSCLC, EGF-induced, A549, } \\
\text { SW-1573 }\end{array}$ & $\begin{array}{l}\Delta^{9} \text {-THC, WIN 55,212-2, } \\
\text { JWH-133 }\end{array}$ & $\begin{array}{l}\text { Inhibition of tumour growth and } \\
\text { reduction in lung metastasis }\end{array}$ & Preet et al. (2008) \\
\hline & $\begin{array}{l}\text { Female NMRI (nu/nu) mice and } \\
\text { human Lung adenocarcinoma, } \\
\text { A549, H460 }\end{array}$ & CBD, AM-251, AM-630 & Reduction in tumour growth & Ramer et al. (2013) \\
\hline & $\begin{array}{l}\text { FVB mice and human Non-small } \\
\text { cell lung cancer (NSCLC); } \\
\text { A549, CALU1. Murine ED1 }\end{array}$ & JWH-015, SR144528 & $\begin{array}{l}\text { Reduction in tumour growth and } \\
\text { metastatic lesions }\end{array}$ & Ravi et al. (2016) \\
\hline BLOOD & Female adult mice C57BL/6 & $\begin{array}{l}\text { CBD, SR141716A, } \\
\text { SR144528 }\end{array}$ & Reduction in tumour growth & McKallip et al. (2006) \\
\hline \multirow[t]{4}{*}{ SKIN } & $\begin{array}{l}\text { C57BL/6 nude mice and murine } \\
\text { melanoma, B16 cell line }\end{array}$ & $\begin{array}{l}\Delta^{9}-\mathrm{THC}, \mathrm{WIN}-55,212-2, \\
\text { SR141716, SR144528 }\end{array}$ & $\begin{array}{l}\text { Decrease in tumour growth, prolifer- } \\
\text { ation, angiogenesis, and metastasis }\end{array}$ & Blázquez et al. (2006) \\
\hline & $\begin{array}{l}\text { Male athymic nude (nu/nu) mice } \\
\text { and human melanoma, CHL-1, } \\
\text { A375, SK-MEL-28BD cell lines }\end{array}$ & $\Delta^{9}-\mathrm{THC}, \mathrm{CBD}$ & Reduction in tumour growth & Ramer et al. (2013) \\
\hline & $\begin{array}{l}\text { NOD/scid/IL-2R gammae } \\
\text { null (NSG) mice and human } \\
\text { myeloma, U266, U266-LR7, } \\
\text { RPMI, RPMI-LR5, MM1.S, } \\
\text { MM1.R cells }\end{array}$ & WIN 55,212-2 & Reduction in tumour growth & Barbado et al. (2017) \\
\hline & $\begin{array}{l}\text { Female C57B6 mice and human } \\
\text { rhabdomyosarcoma, RD, JR1, } \\
\text { RH6, RH2 (ERMS) and RH30, } \\
\text { RH4, RH41, RH3, and RH28 } \\
\text { (ARMS) }\end{array}$ & AM251 & Abrogates lung metastasis formation & Marshall et al. (2011) \\
\hline
\end{tabular}


effects correlated to induction of apoptosis (Massi et al. 2004). Solinas et al. investigated CBD in U87-MG and T98G glioma cell lines and reported inhibition of cell proliferation and invasiveness, a downregulation of ERK and Akt signalling and a decrease in the hypoxia-inducible factor HIF-1 $\alpha$ expression (Solinas et al. 2013). In the following neuroblastoma cell lines, SK-N-SH, IMR-32, NUB-6 and LAN-1, CBD and $\Delta^{9}$-THC treatment induced antitumorigenic activity by decreasing cell viability and invasiveness, arrest of the cell cycle at the $G_{1} / G_{0}$ phase and an increase in activated caspase-3, albeit CBD was more potent in these effects when compared to $\Delta^{9}$-THC (Fisher et al. 2016). Salazar et al. investigated $\Delta^{9}$-THC in the astrocytoma cell line U87MG and in vivo where they report autophagy induction via the upregulation of $\mathrm{p} 8$ leading to apoptosis and inhibition of Akt and mTORC1 (Salazar et al. 2009).

A recent study has reported in the following human glioma cell lines A172, U251, U87 MG, U118 MG and LN18, CBD induced autophagic rather than apoptotic cell death. Specifically, CBD caused mitochondrial dysfunction and lethal mitophagy arrest mechanistically via TRPV4 with an influx of calcium (Huang et al. 2021). Further analysis revealed ER stress and in particular the ATF4DDIT3-TRIB3-AKT-MTOR axis downstream of TRPV4 was involved in CBD's mitophagy effect. Combination of $\mathrm{CBD}$ and temozolomide (TMZ) in neurosphere cultures and mouse models conveyed synergistic effects in reducing tumour burden and improving survival rates (Torres et al. 2011). Their findings suggest a novel TRPV4-CBDmitophagy pathway in glioma and combination of CBD and TMZ as a potential to explore in future clinical studies. Additionally, Vrechi and colleagues show CBD stimulates autophagy signal transduction via crosstalk of ERK1/2 and AKT kinases and that CBD-induced autophagy was reduced in presence of CB receptors and TRPV1 receptor antagonists, AM251, AM630 and capsazepine in neuroblastoma and murine astrocyte cell lines (Vrechi et al. 2021).

Kolbe et al. recently investigated the effects of cannabinoids in glioblastoma multiforme (GBM) cells derived from primary human tumour samples and to identify possible receptors involved. Their findings revealed $\Delta^{9}$-THC reduced the number of Ki67 immuno-reactive nuclei, through GPR55. Their findings suggest that the sensitivity of cannabinoids and receptor-dependent signalling pathways should be considered to reflect the heterogeneity amongst GBM forms which is critical for when evaluating this translationally to clinic (Kolbe et al. 2021). Mutation-driven cancers are important to take into account when tailoring specific treatments. In a recent paper, Ellert-Miklaszewska et al. investigated the use of synthetic cannabinoids in GBM which have frequent TP53 or PTEN genetic defects rendering it from chemotherapy treatments. Their experimental work showed synthetic cannabinoids not only reduce tumour cells but that p53 could also act as an activator or inhibitor of autophagy and apoptosis and this depends on subcellular localisation and the mutant variant of p53 (Ellert-Miklaszewska et al. 2021).

\section{In vivo}

In a glioma mouse model treated with CBD daily at $0.5 \mathrm{mg} /$ mouse, Massi and colleagues reported a significant reduction in xenografted human U87 tumour growth in vivo (Massi et al. 2004). A further study investigating CBD's action in tumours from derived glioma stem cells (GSCs) which known to be resistant to therapies, reported in vivoan increase in the production of ROS leading to the inhibition of cell survival and an increase in the survival rate of mice bearing the GSC xenograft (Singer et al. 2015). They also observed activation of the p-p38 pathway and a downregulation of stem cell regulators including Sox2, Id-1 (a transcription factor involved in cell growth, senescence and differentiation) and p-STAT3 which inhibited the self-renewal of the cells (Singer et al. 2015). Although CBD inhibited glioma progression, a fraction of therapeutic resistance to CBD in a subset of glioma cells was due to the upregulation of antioxidant response genes (Singer et al. 2015). SK-N-SH neuroblastoma cell line induced in nude mice treated with CBD and $\Delta^{9}$-THC led to a reduction in tumour burden and an observed increase in activated caspase-3 (Fisher et al. 2016). Various forms of cannabinoids have been trialled and tested to measure the most efficacious form for oncological effects and these include a pure $(\mathrm{P})$ form versus a botanical drug substance (BDS) which is an active form of the drug that has been cultivated usually available as a powder, tablet or elixir. In a study by Scott et al. using P and BDS forms for both CBD and $\Delta^{9}$-THC, they report efficacious activity for CBD-P in comparison to CBD-BDS and vice versa for $\Delta^{9}$ THC (Scott et al. 2014). As discussed earlier in their in vitrofindings, they report similar outcomes in their orthotopic murine model of glioma and in particular they observed a significant decrease in tumour volumes when both cannabinoids were administered with irradiation, $p<0.001$ (Scott et al. 2014). These findings support the anticancer effects of cannabinoid treatment in glioma as a single therapy and also as an addition in combination treatment.

Cannabinoids share the common anticancer effect of apoptosis in their mode of action; however, it has also become apparent that autophagy is also involved. The process of apoptosis and autophagy interplay, where the survival function of autophagy negatively regulates apoptosis and inhibition of apoptosis blocks autophagy (Marino et al. 2014). Salazar and co-workers investigated $\Delta^{9}$-THC in a murine model of astrocytoma and found that autophagy is upstream of apoptosis in cannabinoid-induced cell death as shown by blocking autophagy, prevented 
cannabinoid-induced apoptosis (Salazar et al. 2009). $\Delta^{9}$ THC induced the effects of stimulation of ceramide synthesis de novo, ER stress, upregulation of $\mathrm{p} 8$ and TRIB3, phosphorylation of eIF2 $\alpha$ on Ser51 via the activation of the $\mathrm{CB}_{1}$ receptor (Salazar et al. 2009). A human glioblastomainduced murine model investigating GICs (glioma initiating cells; a subpopulation of cells responsible for the aggressiveness of GBM) was treated with $\Delta^{9}$-THC, CBD and TMZ in varying combinations. They reported an effective tumour reduction when CBD and $\Delta^{9}$-THC with TMZ were co-administered and that treatment with a high ratio of CBD was most efficacious (López-Valero et al. 2018).

\section{Breast cancer}

\section{In vitro}

McKallip et al. investigated the effects of $\Delta^{9}$-THC in human breast cancer cell lines MDA-MB-231, MCF-7 and mouse mammary carcinoma 4T-1. They reported a low expression of cannabinoid receptors; $\mathrm{CB}_{1}$ and $\mathrm{CB}_{2}$ in these cell lines. $\Delta^{9}$-THC did not affect cell viability in MCF-7 and 4T-1 cell lines but increased the size of a 4T1 primary tumour and enhanced metastasis in vivo. $\Delta^{9}$-THC exposure caused an increase in IL-4 and IL-10 cytokines and suppression of cellmediated Th1 response by enhancement of Th2 cytokines due to upregulation in Th2-related genes. These findings suggest exposure to $\Delta^{9}$-THC may increase susceptibility to breast cancer which does not express cannabinoid receptors and is resistant to $\Delta^{9}$-THC-induced apoptosis (McKallip et al. 2005). In another study by Caffarel and colleagues $\Delta^{9}$-THC was investigated in the following human breast cancer cell lines; MCF-7, EVSA-T, MDA-MB-231, MDAMB468, T-47D and SKBr3. They reported a reduction in human breast cancer cell proliferation by arrest of the cell cycle at the $\mathrm{G}_{2}-\mathrm{M}$ phase via down-regulation of the cyclindependent kinase (CDK1 or Cdc2) protein and an induction of apoptosis via the $\mathrm{CB}_{2}$ cannabinoid receptor which was highly expressed in the EVSA-T cell line. $\mathrm{CB}_{2}$ expression was also found to be correlated with tumours that had a low response to conventional therapies and that were also positive for certain prognostic markers including oestrogen, progesterone receptors and the presence of ERBB2/HER-2 oncogene. The psychotropic effects of cannabinoids are mediated via the $C_{1}$ rather than $C_{2}$, suggesting a cannabinoid therapy that would target the $\mathrm{CB}_{2}$ receptor would be beneficial (Caffarel et al. 2006). In a follow-up study investigating the $\Delta^{9}$-THC antiproliferative mechanism, exposure to $\Delta^{9}$-THC upregulated JunD expression, a proto-oncogene which belongs to the AP-1 transcription factor family, in the tumour cells. In addition, they also identified the involvement of the cyclin-dependent kinase inhibitor p27 and testin (a tumour-suppressor gene) as candidate targets of JunD.
Stress protein $\mathrm{p} 8$, however was involved in $\Delta^{9}$-THC antiproliferative action in a JunD-independent manner, suggesting a multimodal mechanism of action (Caffarel et al. 2008).

In an interesting report by Blasco-Benito et al., they found $\Delta^{9}$-THC was able to disrupt the HER2- $\mathrm{CB}_{2} \mathrm{R}$ complex by selective binding to $\mathrm{CB}_{2} \mathrm{R}$. Additionally, they concluded the antitumour efficacy of a botanical drug preparation to be more potent than pure $\Delta^{9}$-THC for both cell lines and animal studies (Blasco-Benito et al. 2019). Ligresti et al. investigated the anticancer properties of plant-based cannabinoids including CBD, CBG, CBC, CBDA and $\Delta^{9}$-THCA in addition to assessing the use of enriched CBD or $\Delta^{9}$-THC cannabis extracts over pure cannabinoids (Ligresti et al. 2006). Within the breast cancer cell lines, MDA-MB-231 and MCF-7, treated with the above cannabinoids, CBD was the most potent in its antiproliferative activity (Ligresti et al. 2006). They also report CBD mediated its apoptotic effects via the following routes: the direct or indirect activation of the receptors $\mathrm{CB}_{2}$ and TRPV1, receptor-independent elevation of intracellular $\mathrm{Ca}^{2+}$ and ROS generation (Ligresti et al. 2006).

Synthetic agonists or antagonists of cannabinoid receptors have been used to study the role of the ECS in cancer signalling and growth. Sarnataro and co-workers investigated the effects of Rimonabant, a $\mathrm{CB}_{1}$ antagonist, in the invasive human breast cancer line MDA-MB-231 and in the less-invasive lines, T47D and MCF-7 (Sarnataro et al. 2006). Treatment with Rimonabant caused antiproliferative effects characteristic of $\mathrm{G}_{1}-\mathrm{S}$-phase cell cycle arrest accompanied by a downregulation in cyclins $\mathrm{D}$ and $\mathrm{E}$ with associated upregulation of cyclin-dependent kinase inhibitor p2 $7^{\mathrm{KIP} 1}$. No observed apoptosis or necrosis occurred in vitro (Sarnataro et al. 2006). Additionally, within the invasive cells, these effects were found to be associated with lipid $\mathrm{raft} / \mathrm{caveolae}$ as previously shown by the group (Sarnataro et al. 2005). Rimonabant caused complete displacement of the $\mathrm{CB}_{1}$ receptor from lipid rafts and the depletion of cholesterol by methyl- $\beta$-cyclodextrin (MCD) prevented these effects (Sarnataro et al. 2006). In cells overexpressing the $\mathrm{CB}_{1}$ receptor, Rimonabant inhibited MAPK signalling and decreased ERK1/2 activity (Sarnataro et al. 2006). Pre-treatment with MCD before Rimonabant administration caused a depletion in cholesterol and this reverted the inhibitory effects on ERK1/2 via Rimonabant, suggesting an interplay between the $\mathrm{CB}_{1}$ receptor and lipid raft motility in breast tumour growth (Sarnataro et al. 2006). JWH-015, an agonist of the $\mathrm{CB}_{2}$ receptor, in human MCF-7 mammary carcinoma cells reduced viability by inducing apoptosis independent of $\mathrm{G}_{\alpha \mathrm{i}}$ signalling or by pharmacological blockade of $\mathrm{CB}_{1}$, GPR55, TRPV1 or TRPA1 receptors and instead these effects were calcium-dependent and caused changes in MAPK/ERK signalling (Hanlon et al. 2016). 
CBD has also been shown to downregulate Id-1 in the aggressive human breast cancer line MDA-MB-231 through modulation of ERK and ROS pathways leading to a decrease in Id-1 expression and also upregulated Id-2 (a transcriptional regulator) (McAllister et al. 2011). Shrivastava et al. observed a complex interplay between apoptosis and autophagy in CBD-treated invasive breast cancer cells, MDA-MB-231 (Shrivastava et al. 2011). In particular, CBD induced ER stress which led to the inhibition of AKT and mTOR signalling in vitroindicated by low levels of phosphorylated cyclin D1, mTOR and 4EBP1 (Shrivastava et al. 2011). Further analysis revealed CBD inhibited the association between beclin1 (central role in autophagy) and BCL-2 known to inhibit autophagy through cleavage of Beclin- 1 and enhanced the interaction between Beclin-1 and Vps34 favouring autophagy (Shrivastava et al. 2011). Electron microscopy revealed morphological changes to MDAMB-231 CBD-treated cells which included nuclear condensation, margination, increased vacuolization, decrease in intracellular organelles and enlarged mitochondria evident of apoptotic activity (Shrivastava et al. 2011). They hypothesized that the event changes in inducing autophagy may also cause apoptosis as the cleavage product from Beclin-1 translocates to the mitochondria and induces cytochrome $\mathrm{C}$ (Shrivastava et al. 2011). These observations and hypothesis suggest CBD may be able to control the complex interplay between autophagy and apoptosis in these breast cancer cells (Shrivastava et al. 2011). CBD also increased ROS levels and blockage of ROS inhibited apoptotic and autophagy pathways (Shrivastava et al. 2011). These effects were independent of cannabinoid and vanilloid receptor activation (Shrivastava et al. 2011).

Many drugs have failed in clinics for many of the aggressive cancers due to the recalcitrant TME. The TME plays a major role in contributing to the growth and invasion of cancer and in particular tumour-associated macrophages (TAMs) which are a class of immune cells contributing to the immunosuppressive TME through interchange of its two forms: M1 (anti-tumorigenic) and M2 (pro-tumorigenic) (Lin et al. 2019). Elbaz and colleagues investigated CBD in triple-negative breast cancer (TNBC) cell lines SUM159, MDA-MB-231-SCP2, MVT-1, 4T1.2 and in murine leukaemia RAW264.7. They observed CBD inhibited EGF-induced proliferation and chemotaxis in the cell lines, activated EGFR, ERK, Akt, and NF- $\ll$ pathways in addition to inhibition of matrix metallopeptidase 2 and 9 (MMP2 and MMP9) secretion (Elbaz et al. 2015). A cancer education experiment (conditioned media from CBD-treated cancer cells) showed a significant reduction in the number of migrated RAW 264.7 cells towards this medium which also contained lower levels of granulocyte-macrophage colony-stimulating factor (GM-CSF) and chemokine ligand 3 (CCL3) cytokines, crucial for macrophage recruitment and activation (Elbaz et al. 2015). They observed a reduction in tumour growth and metastasis and inhibition of the recruitment of total and M2 macrophages to the stroma of the primary tumour and secondary lung metastasis (Elbaz et al. 2015).

Cannabinoid's effect on ER has been evident in many cancer studies, however, the exact mechanism by which this occurs remain elusive. In a recent study by de la Harpe et al., they found CBD selectively targeted MCF7 cells via oxidative stress-induced ER stress and UPR (unfolded protein response) activation, and these effects were caused by calcium influx via the TRPV1 receptor as opposed to MDAMB-231 cells. This suggests the difference in CBD treatment was dependent on localization of TRPV1 (de la Harpe et al., 2021).

\section{In vivo}

One of the factors to consider in cannabinoid treatment is the abundance of cannabinoid receptors in the tissue of interest. In a study investigating the effects of $\Delta^{9}$-THC in a murine model of mammary carcinoma, it was found that the murine mammary carcinoma cell line 4T1 first did not express detectable levels of the cannabinoid receptors $\mathrm{CB}_{1}$ and $\mathrm{CB}_{2}$ and second, these cells were resistant to the cytotoxicity of $\Delta^{9}$-THC. They also show treatment with $\Delta^{9}$-THC led to an increase in tumour growth and metastasis due to an increase in production of IL-4 and IL-10 which suppressed the cell-mediated Th1 response by enhancing Th2associated cytokines (McKallip et al. 2005). This finding was supported by the injection of anti-IL-4 and anti-IL-10 monoclonal antibodies which partially reversed the immune suppression of $\Delta^{9}$-THC in $4 \mathrm{~T} 1$ cells (McKallip et al. 2005).

A study investigating the effects of the endogenous cannabinoid, Met-F-AEA (a metabolically stable anandamide analogue) in a highly invasive murine breast cancer model reported a significantly reduced amount and size of metastatic nodes and this effect was antagonized by the selective $\mathrm{CB}_{1}$ antagonist Rimonabant (Grimaldi et al. 2006). Molecular interrogation in treated cells with the endogenous cannabinoid caused a decrease in tyrosine phosphorylation of focal adhesion kinase (FAK) and steroid receptor coactivator (Src) and these effects were mitigated by Rimonabant (Grimaldi et al. 2006). They concluded $\mathrm{CB}_{1}$ receptor agonists by modulating FAK phosphorylation inhibited tumour cell invasion and metastasis and therefore $\mathrm{CB}_{1}$ receptor activation may represent a novel therapeutic target for the treatment of breast carcinoma and metastasis (Grimaldi et al. 2006). Rimonabant has also been reported to significantly reduce tumour volume in vivo in the invasive human MDAMD-231 murine model and this effect occurred via the $\mathrm{CB}_{1} \mathrm{R}$ lipid raft/caveolae-mediated mechanism (Sarnataro et al. 2006). 
In a human MDA-MB-231 breast carcinoma xenografted tumour model, both CBD and CBD enriched extract treatment induced apoptosis, inhibited the growth of tumours and metastasis in vivo (Ligresti et al. 2006). CBD has also been shown to modulate transcriptional activity downstream in breast cancer. A study by McAllister and colleagues investigated CBD treatment of a murine model of metastatic breast cancer and found CBD inhibited Id-1 gene expression in the primary tumour and lung metastasis in vivo through modulation of the ERK and ROS pathways (McAllister et al. 2011). Caffarel et al. have shown using a genetically engineered animal model of ErbB2-driven metastatic breast cancer (MMTV-neu mice), $\Delta^{9}$-THC and JWH-133 (selective $\mathrm{CB}_{2}$ agonist) reduce metastatic progression via AKT pathway inhibition (Caffarel et al. 2010).

Cannabinoids mechanistic actions have been reported to be CB-independent with studies reporting other channels through which they may activate their oncological effects, such as GPR55 or vanilloid channels. Hanlon and co-workers report using JWH-015, a $\mathrm{CB}_{2}$ agonist, significantly reduced tumour burden and metastasis of murine mammary carcinoma 4T1 cells in immunocompetent mice and these effects were dependent on calcium and induced changes to MAPK/ERK signalling which were independent of G-protein-coupled signalling, CB or vanilloid receptors (McAllister et al. 2011).

\section{Other gastrointestinal (GI) cancers}

\section{In vitro}

In a study investigating human colorectal cancer cells using the lines DLD-1, CaCo-2 and SW620, treatment with Rimonabant significantly reduced cell proliferation and induced death. In DLD-1 cells, treatment resulted in $\mathrm{G}_{2}-\mathrm{M}$-phase cell cycle arrest without inducing apoptosis or necrosis (Aviello et al. 2012). Further investigation revealed an increase in mitotic catastrophe characterized by changes in the following, cyclin B1, PARP-1 (involved in DNA repair) Aurora B (involved in the attachment of the mitotic spindle in prophase), phosphorylated p38/MAPK and Chk1 (checkpoint kinase 1) in a time-dependent manner (Aviello et al. 2012). Rimonabant, can therefore mediate cancer tumour growth via mitotic catastrophe inducing cell-cycle arrest during spindle assembly and DNA-damage checkpoints (Aviello et al. 2012).

In hepatocellular carcinoma cell lines, HepG2 and Huh-7, treatment with $\Delta^{9}$-THC and JWH-015 (synthetic $\mathrm{CB}_{2}$ receptor agonist) reduced cell viability through activation of the $\mathrm{CB}_{2}$ receptor. Autophagy was subsequently induced by the upregulation of TRIB3, stimulation of adenosine monophosphate-activated kinase (AMPK) and Akt/mTORC1 inhibition (Vara et al. 2011).
In human colorectal cell lines, Caco-2 and HCT116, CBD treatment protected DNA from oxidative damage, reduced cell proliferation and increased endocannabinoid levels via $\mathrm{CB}_{1}$, TRPV1 and PPAR $\gamma$ (Romano et al. 2014). In addition, CBD treatment of colorectal carcinoma cell line DLD1 , reduced cell proliferation (Macpherson et al. 2014). An interesting study investigated the antiproliferative effects of CBD in Caco-2 cell line in various oxygen environments and found the antitumour effects of CBD to be greater in $\mathrm{PhysO}_{2}$ than $\mathrm{AtmosO}_{2}$. They conclude that CBD induced a mitochondrial production of ROS in $\mathrm{PhysO}_{2}$ cells, suggesting that the cellular redox environment can influence how CBD induced antiproliferative effects in $\mathrm{Phys}_{2}$ to $\mathrm{Atmos} \mathrm{O}_{2}$ cells (Nallathambi et al. 2018). This study demonstrates the important role microenvironments play in cell cultures when studying the pharmacokinetics and mechanism of drugs. Macpherson and colleagues report the increase in sensitivity to CBD-induced antiproliferative effects through changes to cell energetics, from a drop in oxygen and a loss in mitochondrial membrane integrity in cells under the atmospheric condition to the increase in ROS in mitochondria under low oxygen conditions (Nallathambi et al. 2018).

Purified cannabinoids have been mainly reported in inducing apoptosis, inhibiting proliferation and metastasis in many cancer types, however, other forms such as unheated extracts of the plants have been less studied. Nallathambi and colleagues identified unheated extract fractions (F7: THCA, F3: CBGA) from C. sativa which displayed cytotoxic effects in colorectal cancer cell lines, HCT116 and CCD-18Co and adenomatous polyps but reduced activity on normal colon cell lines (Nallathambi et al. 2018). Combination treatment analysed by the Bliss independence model, exhibited more potent cytotoxic effects which included cell cycle arrest, cell death and a reduction in genes involved in the Wnt signalling pathway (Proto et al. 2017).

\section{In vivo}

Rimonabant treatment in a mouse model of azoxymethaneinduced colon carcinogenesis caused a significant reduction in aberrant crypt foci formation, which is a neoplastic precursor to colorectal cancer and additionally observed inhibitory effects with changes to mitotic and DNA-damage checkpoints in their cell lines as mentioned previously (Aviello et al. 2012). Another study investigated the synthetic cannabinoids effects on the Wnt/ $\beta$-catenin pathway, a signalling pathway involved in the formation of colorectal cancer (Borelli et al. 2014). The administration of rimonabant in HCT116 xenografts caused a significant reduction in tumour growth and destabilized the nuclear localization of $\beta$-catenin in vivo by inhibiting the canonical Wnt pathway (Borelli et al. 2014). This study suggests a novel use 
for cannabinoids in treating colorectal cancer harbouring mutations in $\beta$-catenin.

In a murine model of hepatocellular carcinoma, treatment with JWH-015 and $\Delta^{9}$-THC, both cannabinoids reduced subcutaneous xenograft growth; however, this effect was not observed when autophagy was pharmacologically inhibited (Vara et al. 2011) indicating the importance of cell death in both cannabinoids reducing tumour burden in vivo. Furthermore, administration of the cannabinoids also led to a reduction in ascites (abnormal build-up of fluid in the abdomen) formation (Vara et al. 2011). In support of the mechanisms observed in the HCC cell lines, Salazar et al. investigated $\Delta^{9}$ THC in the astrocytoma cell line U87MG and in vivo where they report autophagy induction via the upregulation of $\mathrm{p} 8$ leading to apoptosis and inhibition of Akt and mTORC1 (Salazar et al. 2009).

The effect of CBD in gastrointestinal cancers has also been studied. In a study by Aviello et al., CBD treatment in an azoxymethane (AOM)-induced murine model of colon cancer, reduced aberrant crypt foci, polyps, tumour growth and led to a decrease in expression of inducible nitric oxide synthase (iNOS) and phosphorylated Akt with an upregulation in caspase-3 (Aviello et al. 2012). CBG's anticancer effect has been observed in colon cancer models. Borelli et al. evaluated the antineoplastic effects in xenograft models of colon cancer and observed a reduction tumour growth, however due to the limitation in the model, they further tested $\mathrm{CBG}$ in an AOM colon murine model which mimics the tumour in situ and found CBG completely abolished the formation of aberrant crypt foci and reduced the number of tumours (Borelli et al. 2014). In addition, Romano et al. tested the effects of the BDS form of CBD, which contains a high content of CBD on colorectal cancer growth in both xenograft and AOM models. They also observed a reduction in tumour growth, preneoplastic lesions and polyps (Macpherson et al. 2014).

\section{Prostate cancer}

\section{In vitro}

$\Delta^{9}$-THC induced apoptosis in a PC-3 prostate cancer cell line in a dose-dependent manner (Sreevalsan et al. 2011). CBD's pro-apoptotic nature has been shown to be phosphate-dependent in prostate and colon cancer cells (De Petrocellis et al. 2013). In LNCaP (prostate) and SW480 (colon) cancer cell lines, the growth and mRNA expression of several phosphatases inhibited cannabinoid-induced PARP cleavage (De Petrocellis et al. 2013). De Petrocellis et al. investigated CBD's effect in prostate carcinoma cell lines; LNCaP, 22RV1 (positive for androgen receptor), DU-145 and PC-3 (negative for androgen receptor). CBD treatment significantly decreased cell viability and potentiated the effects of bicalutamide and docetaxel (standard drugs for treatment of prostate carcinoma) against $\mathrm{LNCaP}$ and DU-145 xenograft tumours and when given alone reduced LNCaP xenograft size. CBD administered between 1 and $10 \mu \mathrm{M}$ induced apoptosis and markers of intrinsic apoptotic pathways (PUMA, CHOP expression and intracellular $\mathrm{Ca}^{2+}$ ). In $\mathrm{LNCaP}$ cells, the pro-apoptotic effect of CBD was only partly due to TRPM8 antagonism and was accompanied by down-regulation of AR, p53 activation and elevation of ROS. LNCaP cells differentiated to androgen-insensitive neuroendocrine-like cells were more sensitive to CBDinduced apoptosis (De Petrocellis et al. 2013).

\section{Gynaecological cancers}

\section{In vitro}

The effects of $\Delta^{9}$-THC were also investigated in aggressive endometrial cancer. Zhang et al. report in HEC-1B and An3ca aggressive endometrial cancer cell lines a high level of cannabinoid receptor expression and treatment with $\Delta^{9}$-THC inhibited cell viability and motility by inhibiting epithelial-mesenchymal transition (EMT) in addition to down-regulation of the MMP9 gene in inhibiting metastasis. These findings suggest regulation and targeting of the MMP9-related pathways via $\Delta^{9}$-THC treatment may inhibit metastasis in this aggressive cancer type (Zhang et al. 2018). A recent study investigated the oncological effects of CBD as a monotherapy and in combination with chemotherapy drugs in ovarian cancer, administered as Poly lactic-coglycolytic acid (PGLA)-microparticles (Fraguas-Sánchez et al. 2020). Their results show the combination of paclitaxel (PTX) with CBD to be effective in vitro and in ovo (FraguasSánchez et al. 2020). CBD administered as microparticles was more efficacious than in single solution and in ovo, PTX resulted in a 1.5-fold tumour growth inhibition whereas in combination with CBD this increased to a twofold decrease, suggesting a promising therapy to explore in treating ovarian cancer as it provides the advantageous effect of using a lower dose of the antineoplastic drug whilst maintaining the same efficacy (Fraguas-Sánchez et al. 2020).

\section{Clinical studies}

The anticancer effects of cannabinoids have so far been limited to preclinical studies and translation to the clinic has remained stagnant. The first report of the use of cannabinoids on cancer patients was a pilot study that investigated $\Delta^{9}$-THC on nine terminal patients with recurrent glioblastoma where standard therapy remained unhopeful as a curative (Guzmán et al. 2006). These patients underwent intracranial administration of $\Delta^{9}$-THC, as this route was deemed the safest and patients did not exhibit any of the associated 
Table 3 Overview of clinical trials for investigation of cannabinoids in cancer. Key search terms included: "Cancer and Cannabinoids, Cannabis, Cannabidiol, Tetrahydrocannabinol" (www.clinicaltrials.gov)

\begin{tabular}{|c|c|c|c|c|c|c|c|}
\hline Trial name & Conditions & Phase & $\begin{array}{ll}n & \text { Study } \\
\text { type }\end{array}$ & Drug & Location & Status & NCT no. \\
\hline $\begin{array}{l}\text { A Pilot Study of } \\
\text { Dronabinol for } \\
\text { Adult Patients } \\
\text { With Primary } \\
\text { Gliomas }\end{array}$ & $\begin{array}{l}\text { Brain } \\
\text { Neoplasms|NausealVomiting }\end{array}$ & I & $\begin{array}{l}33 \text { Interven- } \\
\text { tional }\end{array}$ & Dronabinol & $\begin{array}{l}\text { North Carlina, } \\
\text { USA }\end{array}$ & $\begin{array}{l}\text { Com- } \\
\text { pleted }\end{array}$ & NCT00314808 \\
\hline $\begin{array}{l}\text { A Phase } 1 \text { Study } \\
\text { of Dexanabinol } \\
\text { in Patients With } \\
\text { Advanced Solid } \\
\text { Tumours }\end{array}$ & Solid Tumour & I & $\begin{array}{l}40 \text { Interven- } \\
\text { tional }\end{array}$ & $\begin{array}{l}\text { DexanabinollOther: } \\
\text { Cremophor }\end{array}$ & $\begin{array}{l}\text { Leeds/Newcastle/ } \\
\text { Glasgow }\end{array}$ & $\begin{array}{l}\text { Com- } \\
\text { pleted }\end{array}$ & NCT01489826 \\
\hline $\begin{array}{l}\text { A Safety Study of } \\
\text { Sativex in Com- } \\
\text { bination With } \\
\text { Dose-intense } \\
\text { Temozolomide } \\
\text { in Patients With } \\
\text { Recurrent Glio- } \\
\text { blastoma }\end{array}$ & Cancer & $\mathrm{I} / \mathrm{II}$ & $\begin{array}{c}6 \text { Interven- } \\
\text { tional }\end{array}$ & Sativex & $\begin{array}{l}\text { Leeds/Bristol/ } \\
\text { London }\end{array}$ & $\begin{array}{l}\text { Com- } \\
\text { pleted }\end{array}$ & NCT01812603 \\
\hline $\begin{array}{l}\text { A Safety Study of } \\
\text { Sativex Com- } \\
\text { pared With Pla- } \\
\text { cebo (Both With } \\
\text { Dose-intense } \\
\text { Temozolomide) } \\
\text { in Recurrent } \\
\text { Glioblastoma } \\
\text { Patients }\end{array}$ & Cancer & $\mathrm{I} / \mathrm{II}$ & $\begin{array}{l}21 \text { Interven- } \\
\text { tional }\end{array}$ & Sativex|Placebo & Germany & $\begin{array}{l}\text { Com- } \\
\text { pleted }\end{array}$ & NCT01812616 \\
\hline $\begin{array}{l}\text { A Pharmacoki- } \\
\text { netic Study of } \\
\text { Single Doses of } \\
\text { Sativex in Treat- } \\
\text { ment-induced } \\
\text { Mucositis }\end{array}$ & $\begin{array}{l}\text { Head and Neck Squamous } \\
\text { Cell Carcinoma }\end{array}$ & I & $\begin{array}{l}10 \text { Interven- } \\
\text { tional }\end{array}$ & Sativex & London & $\begin{array}{r}\text { Termi- } \\
\text { nated }\end{array}$ & NCT01975688 \\
\hline $\begin{array}{l}\text { Assessment of } \\
\text { Single Doses of } \\
\text { Oral Dexanabi- } \\
\text { nol in Healthy } \\
\text { Subjects }\end{array}$ & $\begin{array}{l}\text { Safety|Tolerability|Pharmacok } \\
\text { inetics|Cancer }\end{array}$ & I & $\begin{array}{c}40 \text { Interven- } \\
\text { tional }\end{array}$ & $\begin{array}{l}\text { Dexanabinol, } \\
\text { Placebo }\end{array}$ & Nottingham & $\begin{array}{l}\text { Com- } \\
\text { pleted }\end{array}$ & NCT02054754 \\
\hline $\begin{array}{l}\text { A Study: Pure } \\
\text { CBD as Single- } \\
\text { agent for Solid } \\
\text { Tumor }\end{array}$ & Solid Tumor & II & $\begin{array}{l}60 \text { Interven- } \\
\text { tional }\end{array}$ & Cannabidiol & Israel & $\begin{array}{l}\text { Unknown } \\
\text { status }\end{array}$ & NCT02255292 \\
\hline $\begin{array}{l}\text { A Study of Dexa- } \\
\text { nabinol in Com- } \\
\text { bination With } \\
\text { Chemotherapy } \\
\text { in Patients } \\
\text { With Advanced } \\
\text { Tumours }\end{array}$ & $\begin{array}{l}\text { Hepatocellular } \\
\text { CarcinomalPancreatic } \\
\text { Cancer }\end{array}$ & I & $\begin{array}{c}112 \text { Interven- } \\
\text { tional }\end{array}$ & $\begin{array}{l}\text { Dexanabinoll } \\
\text { Sorafenibl } \\
\text { Nab-paclitaxell } \\
\text { Gemcitabine }\end{array}$ & $\begin{array}{l}\text { Switzerland/Ger- } \\
\text { many/Spain }\end{array}$ & $\begin{array}{l}\text { Unknown } \\
\text { status }\end{array}$ & NCT02423239 \\
\hline $\begin{array}{l}\text { A Study to Assess } \\
\text { the Pharma- } \\
\text { cokinetic (PK) } \\
\text { Properties of } \\
\text { SativexÂA in } \\
\text { Patients With } \\
\text { Advanced } \\
\text { Cancer }\end{array}$ & Advanced Cancer & I & $\begin{array}{c}0 \text { Interven- } \\
\text { tional }\end{array}$ & Sativex & United Kingdom & $\begin{array}{l}\text { With- } \\
\text { drawn }\end{array}$ & NCT02432612 \\
\hline
\end{tabular}


Table 3 (continued)

\begin{tabular}{|c|c|c|c|c|c|c|c|}
\hline Trial name & Conditions & Phase & $\begin{array}{ll}n & \text { Study } \\
\text { type }\end{array}$ & Drug & Location & Status & NCT no. \\
\hline $\begin{array}{l}\text { Study on Cannabi- } \\
\text { noid Receptor } \\
\text { Expression in } \\
\text { Gastrointestinal } \\
\text { Diseases }\end{array}$ & $\begin{array}{c}\text { Ulcerative Colitis|Crohn's } \\
\text { DiseaselColon Cancer }\end{array}$ & - & $\begin{array}{l}31 \text { Observa- } \\
\text { tional }\end{array}$ & N/A & Austria & $\begin{array}{l}\text { Com- } \\
\text { pleted }\end{array}$ & NCT02735941 \\
\hline $\begin{array}{l}\text { The Effect of } \\
\text { Cannabis in Pan- } \\
\text { creatic Cancer }\end{array}$ & $\begin{array}{l}\text { Neoplasms } \\
\text { Pancreatic|Cachexia; } \\
\text { Cancer|Cannabis|Appetite } \\
\text { Loss|Palliative } \\
\text { MedicinelMorbidity|Mortality }\end{array}$ & II & $\begin{array}{l}32 \text { Interven- } \\
\text { tional }\end{array}$ & $\begin{array}{l}\text { THC and CBD } \\
\text { Mixture }\end{array}$ & Denmark & $\begin{array}{l}\text { Unknown } \\
\text { status }\end{array}$ & NCT03245658 \\
\hline $\begin{array}{l}\text { Tolerability of } \\
\text { Cannabis in } \\
\text { Patients Receiv- } \\
\text { ing Concurrent } \\
\text { Chemoradiation } \\
\text { for Glioblastoma }\end{array}$ & Glioblastoma & I & $\begin{array}{c}1 \text { Interven- } \\
\text { tional }\end{array}$ & $\begin{array}{l}\text { Cannabisl Temozo- } \\
\text { lomidel Radiation } \\
\text { Therapy }\end{array}$ & New York, USA & $\begin{array}{r}\text { Termi- } \\
\text { nated }\end{array}$ & NCT03246113 \\
\hline $\begin{array}{l}\text { Medical Cannabis } \\
\text { During Chemo- } \\
\text { radiation for } \\
\text { Head and Neck } \\
\text { Cancer }\end{array}$ & Head and Neck Cancer & - & $\begin{array}{c}30 \text { Observa- } \\
\text { tional }\end{array}$ & Cannabis & New York, USA & $\begin{array}{l}\text { Recruit- } \\
\text { ing }\end{array}$ & NCT03431363 \\
\hline $\begin{array}{l}\text { TN-TC11G } \\
\text { (THC + CBD) } \\
\text { Combination } \\
\text { With Temo- } \\
\text { zolomide and } \\
\text { Radiotherapy in } \\
\text { Patients With } \\
\text { Newly-diagnosed } \\
\text { Glioblastoma }\end{array}$ & Glioblastoma & $\mathrm{I} / \mathrm{II}$ & $\begin{array}{l}30 \text { Interven- } \\
\text { tional }\end{array}$ & $\begin{array}{l}\text { TN-TC11Gl } \\
\text { Temozolomide } \\
\text { Oral Productl } \\
\text { Radiotherapy }\end{array}$ & Spain & $\begin{array}{l}\text { Not yet } \\
\text { recruit- } \\
\text { ing }\end{array}$ & NCT03529448 \\
\hline $\begin{array}{l}\text { A Study of the } \\
\text { Efficacy of } \\
\text { Cannabidiol } \\
\text { in Patients } \\
\text { With Multi- } \\
\text { ple Myeloma, } \\
\text { Glioblastoma } \\
\text { Multiforme, and } \\
\text { GI Malignancies }\end{array}$ & $\begin{array}{l}\text { Cancer of Pancreas|Cancer } \\
\text { of Liver|Cancer of } \\
\text { Rectum|Cancer of } \\
\text { Colon|Cancer, Gall } \\
\text { Bladder|Myeloma } \\
\text { Multiple|Glioblastoma } \\
\text { Multiforme }\end{array}$ & I/ II & $\begin{array}{c}160 \text { Interven- } \\
\text { tional }\end{array}$ & $\begin{array}{l}\text { Cannabidioll } \\
\text { Bortezomibl Leu- } \\
\text { covorinl 5-FUl } \\
\text { Oxaliplatinl } \\
\text { Bevacizumabl } \\
\text { Irinotecanl } \\
\text { Gemcitabinel } \\
\text { Temozolomide }\end{array}$ & $\begin{array}{l}\text { Orlando/Florida, } \\
\text { USA }\end{array}$ & $\begin{array}{l}\text { Not yet } \\
\text { recruit- } \\
\text { ing }\end{array}$ & NCT03607643 \\
\hline $\begin{array}{l}\text { Cannabis Use in } \\
\text { Cancer Patients }\end{array}$ & Solid Tumor, Adult & - & $\begin{array}{c}30 \text { Observa- } \\
\text { tional }\end{array}$ & Cannabis & Colorado, USA & $\begin{array}{l}\text { Recruit- } \\
\text { ing }\end{array}$ & NCT03617692 \\
\hline $\begin{array}{l}\text { Pilot, Syndros, } \\
\text { Decreasing Use } \\
\text { of Opioids in } \\
\text { Breast Cancer } \\
\text { Subjects With } \\
\text { Bone Mets }\end{array}$ & $\begin{array}{l}\text { Bone Metastases/Breast } \\
\text { CancerlPain }\end{array}$ & $\begin{array}{l}\text { Early } \\
\text { I }\end{array}$ & $\begin{array}{l}20 \text { Interven- } \\
\text { tional }\end{array}$ & Syndros & Arizona, USA & $\begin{array}{l}\text { Recruit- } \\
\text { ing }\end{array}$ & NCT03661892 \\
\hline $\begin{array}{l}\text { Pharmacokinetic } \\
\text { (PK) and Phar- } \\
\text { macodynamics } \\
\text { (PD) Study of } \\
\text { Ilera Specific } \\
\text { Products }\end{array}$ & Cancer and other ailments & - & $\begin{array}{c}10 \text { Observa- } \\
\text { tional }\end{array}$ & $\begin{array}{l}\text { RegistrylOther: PK } \\
\text { microsampling of } \\
\text { blood }\end{array}$ & $\begin{array}{l}\text { Philadelphia/ } \\
\text { Pennsylvania, } \\
\text { USA }\end{array}$ & $\begin{array}{l}\text { Termi- } \\
\text { nated }\end{array}$ & NCT03886753 \\
\hline
\end{tabular}


Table 3 (continued)

\begin{tabular}{|c|c|c|c|c|c|c|c|}
\hline Trial name & Conditions & Phase & $\begin{array}{ll}n & \begin{array}{l}\text { Study } \\
\text { type }\end{array}\end{array}$ & Drug & Location & Status & NCT no. \\
\hline $\begin{array}{l}\text { Efficacy and } \\
\text { Safety of Dron- } \\
\text { abinol in the } \\
\text { Improvement of } \\
\text { Chemotherapy- } \\
\text { induced and } \\
\text { Tumor-related } \\
\text { Symptoms in } \\
\text { Advanced Pan- } \\
\text { creatic Cancer }\end{array}$ & $\begin{array}{l}\text { Pancreatic Cancer Non- } \\
\text { resectableIChemotherapy- } \\
\text { induced Nausea and } \\
\text { Vomiting|Pancreatic Cancer } \\
\text { Metastatic }\end{array}$ & III & $\begin{array}{c}140 \text { Interven- } \\
\text { tional }\end{array}$ & $\begin{array}{l}\text { Dronabinol in Oral } \\
\text { Dosage Forml } \\
\text { Placebo in Oral } \\
\text { Dosage Form }\end{array}$ & Austria & $\begin{array}{l}\text { Recruit- } \\
\text { ing }\end{array}$ & NCT03984214 \\
\hline $\begin{array}{l}\text { Dibenzyl Trisul- } \\
\text { phide (GUINE- } \\
\text { AHEN WEED) } \\
\text { for Stage IV } \\
\text { Cancer }\end{array}$ & $\begin{array}{l}\text { Stage IV Prostate } \\
\text { Cancer|Stage IV Colon } \\
\text { Cancer|Stage IV Breast } \\
\text { Cancer|Stage IV Cancer of } \\
\text { the Cervix }\end{array}$ & $\begin{array}{l}\text { Early } \\
\text { I }\end{array}$ & $\begin{array}{c}104 \text { Interven- } \\
\text { tional }\end{array}$ & $\begin{array}{l}\text { Dibenzyl trisul- } \\
\text { phide capsulesl } \\
\text { Placebo }\end{array}$ & Jamaica & $\begin{array}{l}\text { Unknown } \\
\text { status }\end{array}$ & NCT04113096 \\
\hline $\begin{array}{l}\text { Effect of Hemp- } \\
\text { CBD on Patients } \\
\text { With CIPN }\end{array}$ & $\begin{array}{l}\text { Chemotherapy- } \\
\text { induced Peripheral } \\
\text { NeuropathylColorectal } \\
\text { Cancer Stage IIIColorectal } \\
\text { Cancer Stage IIIIBreast } \\
\text { CancerlOvarian } \\
\text { CancerlUterine Cancer }\end{array}$ & II & $\begin{array}{c}100 \text { Interven- } \\
\text { tional }\end{array}$ & $\begin{array}{l}\text { Hemp-based CBDI } \\
\text { Placebo oral } \\
\text { tablet }\end{array}$ & Pennsylvania, USA & $\begin{array}{l}\text { Recruit- } \\
\text { ing }\end{array}$ & NCT04398446 \\
\hline $\begin{array}{l}\text { Epidiolex (CBD) } \\
\text { in Patients With } \\
\text { Biochemically } \\
\text { Recurrent Pros- } \\
\text { tate Cancer }\end{array}$ & $\begin{array}{l}\text { Prostate Cancer } \\
\text { Recurrent|Prostate } \\
\text { Cancer|Prostate Adenocar- } \\
\text { cinoma }\end{array}$ & I & $\begin{array}{c}18 \text { Interven- } \\
\text { tional }\end{array}$ & $\begin{array}{l}\text { Epidiolex Oral } \\
\text { Liquid }\end{array}$ & Kentucky, USA & $\begin{array}{l}\text { Recruit- } \\
\text { ing }\end{array}$ & NCT04428203 \\
\hline
\end{tabular}

psychoactive effects (Guzmán et al. 2006). In-depth analysis of two patients' tumours revealed molecular effects associated with cannabinoids antitumour action, which included decreased cell proliferation, stimulation of apoptosis and autophagy (Guzmán et al. 2006). Although positive effects were observed, the small case number hinders any statistically significant conclusions to be drawn from this study.

A recently published completed clinical study investigated the safety and preliminary efficacy of nabiximols oromucosal cannabinoid spray and dose intense (DIT) TMZ in patients with first recurrence glioblastoma (Twelves et al. 2021). The study included an open label arm where patients received nabiximols $(n=6)$ and a randomised, doubleblind, and placebo-controlled arm $(n=12$ and $n=9)$. Up to 12 sprays/days with DIT for 12 months were administered and the safety, efficacy and pharmacokinetics of TMZ were observed. Study reports a $33 \%$ of nabiximols and placebotreated patients were progression free for 6 months and survival at 1 year for nabiximols was $83 \%$ and $44 \%$ for placebo patients and no effects of nabiximols on TMZ were reported. Although nabiximols spray was tolerable in GBM patients, a major limitation to the study was the small size of enrolled patients, specifically 21 across 9 sites and there was no predetermined power calculation to the study to define the minimum number of patients for statistical power (Twelves et al.
2021). Nevertheless, the observations warrant the need for further clinical trials to help establish safe and efficacious routes of administration, patient sub-stratification and to explore its possible synergistic effects with other antitumour agents as shown in pre-clinical data. Table 3 summarises clinical trials investigating cannabinoids including synthetic versions, CBD and $\Delta^{9}$-THC in cancer treatment.

\section{Conclusion}

Plant-based, endogenous and synthetic cannabinoid compounds have shown merits in not only alleviating the unwanted side effects of antineoplastic drug regiments, but have also shown promising evidence in decreasing tumour burden, and one in vivo study so far concludes increasing survival rates in mice. The antitumour effects of cannabinoids trend in modulating processes which include apoptosis and autophagy through first stimulating de novo synthesis of ceramide which induces activation of ER stress-related signalling proteins further leading to the inhibition of the AKT/mTORC1 axis promoting cell cycle arrest and additional mechanisms, such as cell death and aging. Other pathways involved mechanistically are activation of MAPK/ERK signalling through calcium induction. Strategies that would 
optimize the anticancer effects of cannabinoids through interference of these signalling cross-talks may prove useful for therapeutic intervention. Nevertheless, we found that these effects were reached differently downstream depending on the type of cancer, the dosage of the compound and which receptor/ligands were activated. We also found the co-administration of cannabinoids with chemotherapy drugs enhanced the potency of these effects. These synergistic effects should be targeted for translation to clinical application, especially in cancers which are refractory to chemotherapy. Various extracted forms of cannabinoids from C. sativa have shown varying cytotoxic effects which should be explored in more detail in future studies as majority of the evidence originates from studies investigating mainly $\Delta^{9}$-THC and CBD's actions. Whilst the emerging evidence of phytocannabinoid anticancer effects are promising, there remains a paucity of clinical evaluation which must be overcome.

Funding There were no sources of funding associated with this manuscript.

\section{Declarations}

Conflict of interest On behalf of all authors, the corresponding author states that there is no conflict of interest.

Code of availability Not applicable.

Open Access This article is licensed under a Creative Commons Attribution 4.0 International License, which permits use, sharing, adaptation, distribution and reproduction in any medium or format, as long as you give appropriate credit to the original author(s) and the source, provide a link to the Creative Commons licence, and indicate if changes were made. The images or other third party material in this article are included in the article's Creative Commons licence, unless indicated otherwise in a credit line to the material. If material is not included in the article's Creative Commons licence and your intended use is not permitted by statutory regulation or exceeds the permitted use, you will need to obtain permission directly from the copyright holder. To view a copy of this licence, visit http://creativecommons.org/licenses/by/4.0/.

\section{References}

Afrin F, Chi M, Eamens AL, Duchatel RJ, Douglas AM, Schneider J, Gedye C, Woldu AS, Dun MD (2020) Can hemp help? LowTHC cannabis and non-THC cannabinoids for the treatment of cancer. Cancers (basel) 12(4):1033. https://doi.org/10.3390/cance rs 12041033

Akimov MG, Gamisonia AM, Dudina PV, Gretskaya NM, Gaydaryova AA, Kuznetsov AS, Zinchenko GN, Bezuglov VV (2021) GPR55 receptor activation by the $N$-acyl dopamine family lipids induces apoptosis in cancer cells via the nitric oxide synthase (nNOS) over-stimulation. Int J Mol Sci 22(2):622. https://doi.org/10. 3390/ijms22020622
Andradas C, Blasco-Benito S, Castillo-Lluva S, Dillenburg-Pilla P, Diez-Alarcia R, Juanes-García A, García-Taboada E, HernandoLlorente R, Soriano J, Hamann S, Wenners A, Alkatout I, Klapper W, Rocken C, Bauer M, Arnold N, Quintanilla M, Megías D, Vicente-Manzanares M, Urigüen L, Gutkind JS, Guzmán M, Pérez-Gómez E, Sánchez C (2016) Activation of the orphan receptor GPR55 by lysophosphatidylinositol promotes metastasis in triple-negative breast cancer. Oncotarget 7(30):47565-47575. https://doi.org/10.18632/oncotarget.10206

Andre CM, Hausman J-F, Guerriero G (2016) Cannabis sativa: the plant of the thousand and one molecules. Front Plant Sci 7:19. https://doi.org/10.3389/fpls.2016.00019

Armstrong JL, Hill DS, McKee CS, Hernandez-Tiedra S, Lorente M, Lopez-Valero I, Eleni Anagnostou M, Babatunde F, Corazzari M, Redfern CPF, Velasco G, Lovat PE (2015) Exploiting cannabinoid-induced cytotoxic autophagy to drive melanoma cell death. J Invest Dermatol 135(6):1629-1637. https://doi.org/10. 1038/jid.2015.45

Aviello G, Romano B, Borrelli F, Capasso R, Gallo L, Piscitelli F, Di Marzo V, Izzo AA (2012) Chemopreventive effect of the nonpsychotropic phytocannabinoid cannabidiol on experimental colon cancer. J Mol Med (berl) 90(8):925-934. https://doi.org/ 10.1007/s00109-011-0856-x

Barbado MV, Medrano M, Caballero-Velázquez T, Álvarez-Laderas I, Sánchez-Abarca LI, García-Guerrero E, Martín-Sánchez J, Rosado IV, Piruat JI, Gonzalez-Naranjo P, Campillo NE, Páez JA, Pérez-Simón JA (2017) Cannabinoid derivatives exert a potent anti-myeloma activity both in vitro and in vivo. Int J Cancer 140(3):674-685. https://doi.org/10.1002/ijc.30483

Blasco-Benito S, Moreno E, Seijo-Vila M, Tundidor I, Andradas C, Caffarel MM, Caro-Villalobos M, Urigüen L, Diez-Alarcia R, Moreno-Bueno G, Hernández L, Manso L, Homar-Ruano P, McCormick PJ, Bibic L, Bernadó-Morales C, Arribas J, Canals M, Casadó V, Canela EI, Guzmán M, Pérez-Gómez E, Sánchez $C$ (2019) Therapeutic targeting of HER2- $\mathrm{CB}_{2} \mathrm{R}$ heteromers in HER2-positive breast cancer. Proc Natl Acad Sci USA 116(9):3863-3872. https://doi.org/10.1073/pnas.1815034116

Blázquez C, Carracedo A, Barrado L, Real PJ, Fernández-Luna JL, Velasco G, Malumbres M, Guzmán M (2006) Cannabinoid receptors as novel targets for the treatment of melanoma. FASEB J 20(14):2633-2635. https://doi.org/10.1096/fj.06-6638fje

Borrelli F, Pagano E, Romano B, Panzera S, Maiello F, Coppola D, De Petrocellis L, Buono L, Orlando P, Izzo AA (2014) Colon carcinogenesis is inhibited by the TRPM8 antagonist cannabigerol, a Cannabis-derived non-psychotropic cannabinoid. Carcinogenesis 35(12):2787-2797. https://doi.org/10.1093/carcin/bgu205

Brandi J, Dando I, Palmieri M, Donadelli M, Cecconi D (2013) Comparative proteomic and phosphoproteomic profiling of pancreatic adenocarcinoma cells treated with $\mathrm{CB} 1$ or CB2 agonists. Electrophoresis 34(9-10):1359-1368. https://doi.org/10.1002/ elps.201200402

Brown KJ, Laun AS, Song Z-H (2017) Cannabidiol, a novel inverse agonist for GPR12. Biochem Biophys Res Commun 493(1):451454. https://doi.org/10.1016/j.bbrc.2017.09.001

Caffarel MM, Sarrió D, Palacios J, Guzmán M, Sánchez C (2006) Delta9-tetrahydrocannabinol inhibits cell cycle progression in human breast cancer cells through $\mathrm{Cdc} 2$ regulation. Cancer Res 66(13):6615-6621. https://doi.org/10.1158/0008-5472. CAN-05-4566

Caffarel M, Andradas C, Mira E, Pérez-Gómez E, Cerutti C, MorenoBueno G, Flores JM, García-Real I, Palacios J, Mañes S, Guzmán M, Sánchez C (2010) Cannabinoids reduce ErbB2-driven breast cancer progression through Akt inhibition. Mol Cancer 9:196. https://doi.org/10.1186/1476-4598-9-196

Caffarel M, Moreno-Bueno G, Cerutti C et al (2008) JunD is involved in the antiproliferative effect of $\Delta^{9}$-tetrahydrocannabinol on 
human breast cancer cells. Oncogene 27:5033-5044. https://doi. org/10.1038/onc.2008.145

Calvaruso G, Pellerito O, Notaro A, Giuliano M (2012) Cannabinoidassociated cell death mechanisms in tumor models (review). Int J Oncol 41(2):407-413. https://doi.org/10.3892/ijo.2012.1476

Carracedo A, Lorente M, Egia A, Blázquez C, García S, Giroux V, Malicet C, Villuendas R, Gironella M, González-Feria L, Piris MA, Iovanna JL, Guzmán M, Velasco G (2006) The stressregulated protein $\mathrm{p} 8$ mediates cannabinoid-induced apoptosis of tumor cells. Cancer Cell 9(4):301-312. https://doi.org/10.1016/j. ccr.2006.03.005

Chakravarti B, Ravi J, Ganju RK (2014) Cannabinoids as therapeutic agents in cancer: current status and future implications. Oncotarget 5(15):5852-5872. https://doi.org/10.18632/oncotarget. v5i15

Console-Bram L, Brailoiu E, Brailoiu GC, Sharir H, Abood ME (2014) Activation of GPR18 by cannabinoid compounds: a tale of biased agonism. Br J Pharmacol 171(16):3908-3917. https://doi.org/10. 1111/bph.12746

Dando I, Donadelli M, Costanzo C, Dalla Pozza E, D’Alessandro A, Zolla L, Palmieri M (2013) Cannabinoids inhibit energetic metabolism and induce AMPK-dependent autophagy in pancreatic cancer cells. Cell Death Dis 4(6):e664. https://doi.org/10. 1038/cddis.2013.151

Dariš B, Tancer Verboten M, Knez Ž, Ferk P (2019) Cannabinoids in cancer treatment: therapeutic potential and legislation. Bosn J Basic Med Sci 19(1):14-23. https://doi.org/10.17305/bjbms. 2018.3532

de la Harpe A, Beukes N, Frost CL (2021) CBD activation of TRPV1 induces oxidative signaling and subsequent ER stress in breast cancer cell lines. Biotechnol Appl Biochem. https://doi.org/10. 1002/bab.2119

De Petrocellis L, Ligresti A, Schiano Moriello A, Iappelli M, Verde R, Stott CG, Cristino L, Orlando P, Di Marzo V (2013) NonTHC cannabinoids inhibit prostate carcinoma growth in vitro and in vivo: pro-apoptotic effects and underlying mechanisms. Br J Pharmacol 168(1):79-102. https://doi.org/10.1111/j.1476-5381. 2012.02027

Donadelli M, Dando I, Zaniboni T, Costanzo C, Dalla Pozza E, Scupoli MT, Scarpa A, Zappavigna S, Marra M, Abbruzzese A, Bifulco M, Caraglia M, Palmieri M (2011) Gemcitabine/cannabinoid combination triggers autophagy in pancreatic cancer cells through a ROS-mediated mechanism. Cell Death Dis 2(4):e152. https://doi.org/10.1038/cddis.2011.36

Elbaz M et al (2015) Modulation of the tumor microenvironment and inhibition of EGF/EGFR pathway: novel anti-tumor mechanisms of Cannabidiol in breast cancer. Mol Oncol 9(4):906-919. https://doi.org/10.1016/j.molonc.2014.12.010

Ellert-Miklaszewska A, Ciechomska IA, Kaminska B (2021) Synthetic cannabinoids induce autophagy and mitochondrial apoptotic pathways in human glioblastoma cells independently of deficiency in TP53 or PTEN tumor suppressors. Cancers 13(3):419. https://doi.org/10.3390/cancers13030419

Ellert-Miklaszewska A, Ciechomska IA, Kaminska B (2021) Synthetic cannabinoids induce autophagy and mitochondrial apoptotic pathways in human glioblastoma cells independently of deficiency in TP53 or PTEN tumor suppressors. Cancers (basel) 13(3):419. https://doi.org/10.3390/cancers13030419

ElSohly MA et al (2017) Phytochemistry of Cannabis sativa L. Prog Chem Org Nat Prod. https://doi.org/10.1007/ 978-3-319-45541-9_1

Falasca M, Ferro R (2016) Role of the lysophosphatidylinositol/GPR55 axis in cancer. Adv Biol Regul. https://doi.org/10.1016/j.jbior. 2015.10.003

Ferro R et al (2018) GPR55 signalling promotes proliferation of pancreatic cancer cells and tumour growth in mice, and its inhibition increases effects of gemcitabine. Oncogene 37(49):6368-6382. https://doi.org/10.1038/s41388-018-0390-1

Fiore D, Ramesh P, Proto MC, Piscopo C, Franceschelli S, Anzelmo S, Medema JP, Bifulco M, Gazzerro P (2018) Rimonabant kills colon cancer stem cells without inducing toxicity in normal colon organoids. Front Pharmacol 8:949. https://doi.org/10.3389/fphar. 2017.00949

Fisher T, Golan H, Schiby G, PriChen S, Smoum R, Moshe I, PeshesYaloz N, Castiel A, Waldman D, Gallily R, Mechoulam R, Toren A (2016) In vitro and in vivo efficacy of non-psychoactive cannabidiol in neuroblastoma. Curr Oncol 23(2):S15-22. https://doi. org/10.3747/co.23.2893

Fogli S, Nieri P, Chicca A, Adinolfi B, Mariotti V, Iacopetti P, Breschi MC, Pellegrini S (2006) Cannabinoid derivatives induce cell death in pancreatic MIA PaCa-2 cells via a receptor-independent mechanism. FEBS Lett 580(7):1733-1739. https://doi.org/10. 1016/j.febslet.2006.02.024

Fraguas-Sánchez AI, Fernández-Carballido A, Simancas-Herbada R, Martin-Sabroso C, Torres-Suárez AI (2020) CBD loaded microparticles as a potential formulation to improve paclitaxel and doxorubicin-based chemotherapy in breast cancer. Int J Pharm 25(574):118916. https://doi.org/10.1016/j.ijpharm.2019.118916

Franco R, Rivas-Santisteban R, Reyes-Resina I, Casanovas M, PérezOlives C, Ferreiro-Vera C, Navarro G, Sánchez de Medina V, Nadal X (2020) Pharmacological potential of varinic-, minor-, and acidic phytocannabinoids. Pharmacol Res 158:104801. https://doi.org/10.1016/j.phrs.2020.104801

Gazzerro P, Malfitano AM, Proto MC, Santoro A, Pisanti S, Caruso MG, Notarnicola M, Messa C, Laezza C, Misso G, Caraglia M, Bifulco M (2010) Synergistic inhibition of human colon cancer cell growth by the cannabinoid CB1 receptor antagonist rimonabant and oxaliplatin. Oncol Rep 23(1):171-175

Gómez del Pulgar T, Velasco G, Sánchez C, Haro A, Guzmán M (2002) De novo-synthesized ceramide is involved in cannabinoidinduced apoptosis. Biochem J 363(Pt 1):183-8. https://doi.org/ 10.1042/0264-6021:3630183

Gonçalves ECD, Baldasso GM, Bicca MA, Paes RS, Capasso R, Dutra RC (2020) Terpenoids, cannabimimetic ligands, beyond the Cannabis plant. Molecules 25(7):1567. https://doi.org/10.3390/molec ules 25071567

Grimaldi C, Pisanti S, Laezza C, Malfitano AM, Santoro A, Vitale M, Caruso MG, Notarnicola M, Iacuzzo I, Portella G, Di Marzo V, Bifulco M (2006) Anandamide inhibits adhesion and migration of breast cancer cells. Exp Cell Res 312(4):363-373. https://doi. org/10.1016/j.yexcr.2005.10.024

Guerrero-Alba R et al (2019) Some prospective alternatives for treating pain: the endocannabinoid system and its putative receptors GPR18 and GPR55. Front Pharmacol 9:1496. https://doi.org/10. 3389/fphar.2018.01496

Guindon J, Hohmann A (2012) The endocannabinoid system and pain. CNS Neurol Disord Drug Targets. https://doi.org/10.2174/18715 2709789824660

Gustafsson K, Sander B, Bielawski J, Hannun YA, Flygare J (2009) Potentiation of cannabinoid-induced cytotoxicity in mantle cell lymphoma through modulation of ceramide metabolism. Mol Cancer Res MCR 7(7):1086-1098. https://doi.org/10.1158/15417786.MCR-08-0361

Guzmán M, Duarte MJ, Blázquez C, Ravina J, Rosa MC, Galve-Roperh I, Sánchez C, Velasco G, González-Feria L (2006) A pilot clinical study of Delta9-tetrahydrocannabinol in patients with recurrent glioblastoma multiforme. Br J Cancer 95(2):197-203. https://doi.org/10.1038/sj.bjc.6603236

Gyombolai P et al (2012) Regulation of endocannabinoid release by $\mathrm{G}$ proteins: a paracrine mechanism of $\mathrm{G}$ protein-coupled receptor action. Mol Cell Endocrinol. https://doi.org/10.1016/j.mce. 2011.10.011 
Hanahan D, Weinberg RA (2000) The hallmarks of cancer. Cell. https://doi.org/10.1016/S0092-8674(00)81683-9

Hanahan D, Weinberg RA (2011) Hallmarks of cancer: the next generation. Cell. https://doi.org/10.1016/j.cell.2011.02.013

Hanlon KE, Lozano-Ondoua AN, Umaretiya PJ, Symons-Liguori AM, Chandramouli A, Moy JK, Kwass WK, Mantyh PW, Nelson MA, Vanderah TW (2016) Modulation of breast cancer cell viability by a cannabinoid receptor 2 agonist, JWH-015, is calcium dependent. Breast Cancer (dove Med Press) 15(8):59-71. https:// doi.org/10.2147/BCTT.S100393

Hart S, Fischer OM, Axel U (2004) Cannabinoids induce cancer cell proliferation via tumor necrosis factor $\alpha$-converting enzyme (TACE/ADAM17)-mediated transactivation of the epidermal growth factor receptor. Cancer Res 64(6):1943-1950. https:// doi.org/10.1158/0008-5472.CAN-03-3720

Hernández-Tiedra S, Fabriàs G, Dávila D, Salanueva ÍJ, Casas J, Montes LR, Antón Z, García-Taboada E, Salazar-Roa M, Lorente M, Nylandsted J, Armstrong J, López-Valero I, McKee CS, Serrano-Puebla A, García-López R, González-Martínez J, Abad JL, Hanada K, Boya P, Goñi F, Guzmán M, Lovat P, Jäättelä M, Alonso A, Velasco G (2016) Dihydroceramide accumulation mediates cytotoxic autophagy of cancer cells via autolysosome destabilization. Autophagy 12(11):2213-2229. https://doi.org/ 10.1080/15548627.2016.1213927

Hirao-Suzuki M, Takeda S, Koga T, Takiguchi M, Toda A (2020) Cannabidiolic acid dampens the expression of cyclooxygenase- 2 in MDA-MB-231 breast cancer cells: possible implication of the peroxisome proliferator-activated receptor $\beta / \delta$ abrogation. J Toxicol Sci 45(4):227-236. https://doi.org/10.2131/jts.45.227

Howlett AC (2005) Cannabinoid receptor signaling. Handb Exp Pharmacol 168:53-79. https://doi.org/10.1007/3-540-26573-2_2

Huang T, Xu T, Wang Y, Zhou Y, Yu D, Wang Z, He L, Chen Z, Zhang Y, Davidson D, Dai Y, Hang C, Liu X, Yan C (2021) Cannabidiol inhibits human glioma by induction of lethal mitophagy through activating TRPV4. Autophagy 25:1-15. https://doi.org/10.1080/ 15548627.2021.1885203

Ibeas Bih C, Chen T, Nunn AV, Bazelot M, Dallas M, Whalley BJ (2015) Molecular targets of cannabidiol in neurological disorders. Neurotherapeutics 12(4):699-730. https://doi.org/10.1007/ s13311-015-0377-3

Javid FA, Phillips RM, Afshinjavid S, Verde R, Ligresti A (2016) Cannabinoid pharmacology in cancer research: a new hope for cancer patients? Eur J Pharmacol 775:1-14. https://doi.org/10.1016/j. ejphar.2016.02.010

Jung CK, Kang WK, Park JM, Ahn HJ, Kim SW, Taek OS, Choi KY (2013) Expression of the cannabinoid type I receptor and prognosis following surgery in colorectal cancer. Oncol Lett 5(3):870876. https://doi.org/10.3892/ol.2012.1081

Kalant H (2001) Medicinal use of cannabis: history and current status. Pain Res Manage 6(2):80-91. https://doi.org/10.1155/2001/ 469629

Kalenderoglou N, Macpherson T, Wright KL (2017) Cannabidiol reduces leukemic cell size-but is it important? Front Pharmacol 8:144. https://doi.org/10.3389/fphar.2017.00144

Kaur R, Ambwani RS, Singh S (2016) Endocannabinoid system: a multi-facet therapeutic target. Curr Clin Pharmacol. https://doi. org/10.2174/1574884711666160418105339

Khan MI, Sobocińska AA, Brodaczewska KK, Zielniok K, Gajewska M, Kieda C, Czarnecka AM, Szczylik C (2018) Involvement of the $\mathrm{CB}_{2}$ cannabinoid receptor in cell growth inhibition and $\mathrm{G} 0 /$ G1 cell cycle arrest via the cannabinoid agonist WIN 55,212-2 in renal cell carcinoma. BMC Cancer 18(1):583. https://doi.org/ 10.1186/s12885-018-4496-1

Kleckner AS et al (2019) Opportunities for cannabis in supportive care in cancer. Ther Adv Med Oncol. https://doi.org/10.1177/17588 35919866362
Kolbe MR, Hohmann T, Hohmann U, Ghadban C, Mackie K, Zöller C, Prell J, Illert J, Strauss C, Dehghani F (2021) THC Reduces Ki67-Immunoreactive Cells Derived from Human Primary Glioblastoma in a GPR55-Dependent Manner. Cancers (basel) 13(5):1064. https://doi.org/10.3390/cancers13051064

Ladin DA, Soliman E, Griffin L, Van Dross R (2016) Preclinical and clinical assessment of cannabinoids as anti-cancer agents. Front Pharmacol 7(7):361. https://doi.org/10.3389/fphar.2016.00361

Lee JLC, Bertoglio LJ, Guimarães FS, Stevenson CW (2017) Cannabidiol regulation of emotion and emotional memory processing: relevance for treating anxiety-related and substance abuse disorders. Br J Pharmacol 174(19):3242-3256. https://doi.org/ 10.1111/bph.13724

Levy M, Futerman AH (2010) Mammalian ceramide synthases. IUBMB Life 62(5):347-356. https://doi.org/10.1002/iub.319

Ligresti A, Moriello AS, Starowicz K, Matias I, Pisanti S, De Petrocellis L, Laezza C, Portella G, Bifulco M, Di Marzo V (2006) Antitumor activity of plant cannabinoids with emphasis on the effect of cannabidiol on human breast carcinoma. J Pharmacol Exp Ther 318(3):1375-1387. https://doi.org/10.1124/jpet.106.105247

Lin Y, Xu J, Lan H (2019) Tumor-associated macrophages in tumor metastasis: biological roles and clinical therapeutic applications. J Hematol Oncol 12:76. https://doi.org/10.1186/ s13045-019-0760-3

López-Valero I, Saiz-Ladera C, Torres S, Hernández-Tiedra S, GarcíaTaboada E, Rodríguez-Fornés F, Barba M, Dávila D, SalvadorTormo N, Guzmán M, Sepúlveda JM, Sánchez-Gómez P, Lorente M, Velasco G (2018) Targeting glioma initiating cells with A combined therapy of cannabinoids and temozolomide. Biochem Pharmacol 157:266-274. https://doi.org/10.1016/j.bcp.2018.09. 007

Lorente M, Torres S, Salazar M, Carracedo A, Hernández-Tiedra S, Rodríguez-Fornés F, García-Taboada E, Meléndez B, Mollejo M, Campos-Martín Y, Lakatosh SA, Barcia J, Guzmán M, Velasco G (2011) Stimulation of the midkine/ALK axis renders glioma cells resistant to cannabinoid antitumoral action. Cell Death Differ 18(6):959-973. https://doi.org/10.1038/cdd.2010.170

Lu H-C, Mackie K (2016) An introduction to the endogenous cannabinoid system. Biol Psychiat 79(7):516-525. https://doi.org/ 10.1016/j.biopsych.2015.07.028

Macpherson T, Armstrong JA, Criddle DN, Wright KL (2014) Physiological intestinal oxygen modulates the Caco-2 cell model and increases sensitivity to the phytocannabinoid cannabidiol. Vitro Cell Dev Biol Anim 50(5):417-426. https://doi.org/10.1007/ s11626-013-9719-9

Marcu JP, Christian RT, Lau D, Zielinski AJ, Horowitz MP, Lee J, Pakdel A, Allison J, Limbad C, Moore DH, Yount GL, Desprez PY, McAllister SD (2010) Cannabidiol enhances the inhibitory effects of delta9-tetrahydrocannabinol on human glioblastoma cell proliferation and survival. Mol Cancer Ther 9(1):180-189. https://doi.org/10.1158/1535-7163.MCT-09-0407

Mariño G, Niso-Santano M, Baehrecke EH, Kroemer G (2014) Selfconsumption: the interplay of autophagy and apoptosis. Nat Rev Mol Cell Biol 15(2):81-94. https://doi.org/10.1038/nrm3735

Marshall AD, Lagutina I, Grosveld GC (2011) PAX3-FOXO1 induces cannabinoid receptor 1 to enhance cell invasion and metastasis. Cancer Res 71(24):7471-7481. https://doi.org/10.1158/00085472.CAN-11-0924

Massi P, Vaccani A, Ceruti S, Colombo A, Abbracchio MP, Parolaro D (2004) Antitumor effects of cannabidiol, a nonpsychoactive cannabinoid, on human glioma cell lines. J Pharmacol Exp Ther 308(3):838-845. https://doi.org/10.1124/jpet.103.061002

Matas D, Juknat A, Pietr M, Klin Y, Vogel Z (2007) Anandamide protects from low serum-induced apoptosis via its degradation to ethanolamine. J Biol Chem 282(11):7885-7892. https://doi. org/10.1074/jbc.M608646200 
McAllister SD, Murase R, Christian RT, Lau D, Zielinski AJ, Allison J, Almanza C, Pakdel A, Lee J, Limbad C, Liu Y, Debs RJ, Moore DH, Desprez PY (2011) Pathways mediating the effects of cannabidiol on the reduction of breast cancer cell proliferation, invasion, and metastasis. Breast Cancer Res Treat 129(1):37-47. https://doi.org/10.1007/s10549-010-1177-4 (Erratum in: Breast Cancer Res Treat. 2012 May;133(1):401-4)

McKallip RJ, Nagarkatti M, Nagarkatti PS (2005) $\Delta-9$ tetrahydrocannabinol enhances breast cancer growth and metastasis by suppression of the antitumor immune response. J Immunol 174(6):3281-3289. https://doi.org/10.4049/jimmunol.174.6. 3281

McKallip RJ, Jia W, Schlomer J, Warren JW, Nagarkatti PS, Nagarkatti M (2006) Cannabidiol-induced apoptosis in human leukemia cells: a novel role of cannabidiol in the regulation of $\mathrm{p} 22 \mathrm{phox}$ and Nox4 expression. Mol Pharmacol 70(3):897-908. https://doi. org/10.1124/mol.106.023937

McPartland JM (2018) 'Cannabis systematics at the levels of family, genus, and species. Cannabis Cannabinoid Res. https://doi.org/ 10.1089/can.2018.0039

Millar SA, Stone NL, Yates AS, O'Sullivan SE (2018) A systematic review on the pharmacokinetics of cannabidiol in humans. Front Pharmacol 26(9):1365. https://doi.org/10.3389/fphar.2018.01365

Mimeault M, Pommery N, Wattez N, Bailly C, Hénichart JP (2003) Anti-proliferative and apoptotic effects of anandamide in human prostatic cancer cell lines: implication of epidermal growth factor receptor down-regulation and ceramide production. Prostate 56:1-12. https://doi.org/10.1002/pros. 10190

Mohammadpour F et al (2017) Anti-invasion effects of cannabinoids agonist and antagonist on human breast cancer stem cells. Iran J Pharm Res. https://doi.org/10.22037/ijpr.2017.2143

Morales P, Reggio PH, Jagerovic N (2017) An overview on medicinal chemistry of synthetic and natural derivatives of cannabidiol. Front Pharmacol 8:422. https://doi.org/10.3389/fphar.2017. 00422

Morell C, Bort A, Vara D, Ramos-Torres A, Rodríguez-Henche N, Díaz-Laviada I (2016) The cannabinoid WIN 55,212-2 prevents neuroendocrine differentiation of $\mathrm{LNCaP}$ prostate cancer cells. Prostate Cancer Prostatic Dis 19(3):248-257. https://doi.org/10. 1038/pcan.2016.19

Moreno E, Cavic M, Krivokuca A, Casadó V, Canela E (2019) The endocannabinoid system as a target in cancer diseases: are we there yet? Front Pharmacol 10:339. https://doi.org/10.3389/fphar. 2019.00339

Müller L, Radtke A, Decker J, Koch M, Belge G (2017) The synthetic cannabinoid WIN 55,212-2 elicits death in human cancer cell lines. Anticancer Res 37(11):6341-6345. https://doi.org/10. 21873/anticanres. 12086

Munson AE, Harris LS, Friedman MA, Dewey WL, Carchman RA (1975) Antineoplastic activity of cannabinoids. J Natl Cancer Inst 55(3):597-602. https://doi.org/10.1093/jnci/55.3.597

Nallathambi R, Mazuz M, Namdar D, Shik M, Namintzer D, Vinayaka AC, Ion A, Faigenboim A, Nasser A, Laish I, Konikoff FM, Koltai H (2018) Identification of synergistic interaction between cannabis-derived compounds for cytotoxic activity in colorectal cancer cell lines and colon polyps that induces apoptosis-related cell death and distinct gene expression. Cannabis Cannabinoid Res 3(1):120-135. https://doi.org/10.1089/can.2018.0010

Ngwa W, Kumar R, Moreau M, Dabney R, Herman A (2017) Nanoparticle drones to target lung cancer with radiosensitizers and cannabinoids. Front Oncol 7:208. https://doi.org/10.3389/fonc. 2017.00208

Ngwa W, Irabor OC, Schoenfeld JD, Hesser J, Demaria S, Formenti SC (2018) Using immunotherapy to boost the abscopal effect. Nat Rev Cancer 18(5):313-322. https://doi.org/10.1038/nrc.2018.6
O'Shaughnessy WB (1843) On the preparations of the Indian Hemp, or gunjah*. Prov Med Surg J. https://doi.org/10.1136/bmj.1.2629. 1171

Ohoka N, Yoshii S, Hattori T, Onozaki K, Hayashi H (2005) TRB3, a novel ER stress-inducible gene, is induced via ATF4-CHOP pathway and is involved in cell death. EMBO J 24(6):1243-1255. https://doi.org/10.1038/sj.emboj.7600596

Orellana-Serradell O, Poblete CE, Sanchez C, Castellón EA, Gallegos I, Huidobro C, Llanos MN, Contreras HR (2015) Proapoptotic effect of endocannabinoids in prostate cancer cells. Oncol Rep 33(4):1599-1608. https://doi.org/10.3892/or.2015.3746

Ortega A, García-Hernández VM, Ruiz-García E, Meneses-García A, Herrera-Gómez A, Aguilar-Ponce JL, Montes-Servín E, Prospero-García O, Del Angel SA (2016) Comparing the effects of endogenous and synthetic cannabinoid receptor agonists on survival of gastric cancer cells. Life Sci 15(165):56-62. https:// doi.org/10.1016/j.lfs.2016.09.010

Parker LA, Rock EM, Limebeer CL (2011) Regulation of nausea and vomiting by cannabinoids. Br J Pharmacol. https://doi.org/10. 1111/j.1476-5381.2010.01176.x

Pellati F, Borgonetti V, Brighenti V, Biagi M, Benvenuti S, Corsi L (2018) Cannabis sativa L. and nonpsychoactive cannabinoids: their chemistry and role against oxidative stress, inflammation, and cancer. Biomed Res Int 2018:1691428. https://doi.org/10. $1155 / 2018 / 1691428$

Pertwee RG (2006) Cannabinoid pharmacology: the first 66 years. Br J Pharmacol. https://doi.org/10.1038/sj.bjp.0706406

Pietrovito L et al (2020) Treatment with cannabinoids as a promising approach for impairing fibroblast activation and prostate cancer progression. Int J Mol Sci. https://doi.org/10.3390/ijms21030787

Pisanti S et al (2013) The endocannabinoid signaling system in cancer. Trends Pharmacol Sci. https://doi.org/10.1016/j.tips.2013.03.003

Pistis M, O'Sullivan SE (2017) The role of nuclear hormone receptors in cannabinoid function. Adv Pharmacol. https://doi.org/10.1016/ bs.apha.2017.03.008

Powles T, te Poele R, Shamash J, Chaplin T, Propper D, Joel S, Oliver T, Liu WM (2005) Cannabis-induced cytotoxicity in leukemic cell lines: the role of the cannabinoid receptors and the MAPK pathway. Blood 105(3):1214-1221. https://doi.org/10.1182/ blood-2004-03-1182

Preet A, Ganju R, Groopman J (2008) $\Delta^{9}$-Tetrahydrocannabinol inhibits epithelial growth factor-induced lung cancer cell migration in vitro as well as its growth and metastasis in vivo. Oncogene 27:339-346. https://doi.org/10.1038/sj.onc.1210641

Proto MC, Fiore D, Piscopo C et al (2017) Inhibition of Wnt/ $\beta$-Catenin pathway and Histone acetyltransferase activity by Rimonabant: a therapeutic target for colon cancer. Sci Rep 7:11678. https://doi. org/10.1038/s41598-017-11688-X

Qamri Z, Preet A, Nasser MW, Bass CE, Leone G, Barsky SH, Ganju RK (2009) Synthetic cannabinoid receptor agonists inhibit tumor growth and metastasis of breast cancer. Mol Cancer Ther 8(11):3117-3129. https://doi.org/10.1158/1535-7163. MCT-09-0448

Ramer R, Heinemann K, Merkord J, Rohde H, Salamon A, Linnebacher M, Hinz B (2013) COX-2 and PPAR- $\gamma$ confer cannabidiolinduced apoptosis of human lung cancer cells. Mol Cancer Ther 12(1):69-82. https://doi.org/10.1158/1535-7163.MCT-12-0335

Ravi J, Elbaz M, Wani NA, Nasser MW, Ganju RK (2016) Cannabinoid receptor-2 agonist inhibits macrophage induced EMT in nonsmall cell lung cancer by downregulation of EGFR pathway. Mol Carcinog 55(12):2063-2076. https://doi.org/10.1002/mc.22451

Romano B, Borrelli F, Pagano E, Cascio MG, Pertwee RG, Izzo AA (2014) Inhibition of colon carcinogenesis by a standardized Cannabis sativa extract with high content of cannabidiol. Phytomedicine 21(5):631-639. https://doi.org/10.1016/j.phymed. 2013.11.006 
Ruiz L, Miguel A, Diaz-Laviada I (1999) v9-Tetrahydrocannabinol induces apoptosis in human prostate PC-3 cells via a receptorindependent mechanism. FEBS Lett. https://doi.org/10.1016/ S0014-5793(99)01073-X

Salazar M, Carracedo A, Salanueva ÍJ, Hernández-Tiedra S, Lorente $M$ et al (2009) Cannabinoid action induces autophagy-mediated cell death through stimulation of ER stress in human glioma cells. J Clin Investig 119(5):1359-1372. https://doi.org/10.1172/ jci37948

Sanchez MG, Sanchez AM, Ruiz-Llorente L, Diaz-Laviada I (2003) Enhancement of androgen receptor expression induced by (R)methanandamide in prostate LNCaP cells. FEBS Lett 555:561566. https://doi.org/10.1016/s0014-5793(03)01349-8

Santoro A, Pisanti S, Grimaldi C, Izzo AA, Borrelli F, Proto MC, Malfitano AM, Gazzerro P, Laezza C, Bifulco M (2009) Rimonabant inhibits human colon cancer cell growth and reduces the formation of precancerous lesions in the mouse colon. Int J Cancer 125(5):996-1003. https://doi.org/10.1002/ijc.24483

Sarfaraz S, Afaq F, Adhami VM, Malik A, Mukhtar H (2006) Cannabinoid receptor agonist-induced apoptosis of human prostate cancer cells LNCaP proceeds through sustained activation of ERK1/2 leading to G1 cell cycle arrest. J Biol Chem 281:39480-39491

Sarnataro D, Grimaldi C, Pisanti S, Gazzerro P, Laezza C, Zurzolo C, Bifulco M (2005) Plasma membrane and lysosomal localization of CB1 cannabinoid receptor are dependent on lipid rafts and regulated by anandamide in human breast cancer cells. FEBS Lett 579(28):6343-6349. https://doi.org/10.1016/j.febslet.2005. 10.016

Sarnataro D, Pisanti S, Santoro A, Gazzerro P, Malfitano AM, Laezza C, Bifulco M (2006) The cannabinoid CB1 receptor antagonist rimonabant (SR141716) inhibits human breast cancer cell proliferation through a lipid raft-mediated mechanism. Mol Pharmacol 70(4):1298-1306. https://doi.org/10.1124/mol.106.025601

Schiffmann S, Sandner J, Birod K, Wobst I, Angioni C, Ruckhäberle E, Kaufmann M, Ackermann H, Lötsch J, Schmidt H, Geisslinger G, Grösch S (2009) Ceramide synthases and ceramide levels are increased in breast cancer tissue. Carcinogenesis 30(5):745-752. https://doi.org/10.1093/carcin/bgp061

Schoeman R, Beukes N, Frost C (2020) Cannabinoid combination induces cytoplasmic vacuolation in MCF-7 breast cancer cells. Molecules (basel, Switzerland) 25(20):4682. https://doi.org/10. 3390/molecules25204682

Schröder M, Kaufman RJ (2005) The mammalian unfolded protein response. Annu Rev Biochem 74(1):739-789. https://doi.org/10. 1146/annurev.biochem.73.011303.074134

Scott KA, Dalgleish AG, Liu WM (2014) The combination of cannabidiol and D 9-tetrahydrocannabinol enhances the anticancer effects of radiation in an orthotopic murine glioma model. Mol Cancer Ther. https://doi.org/10.1158/1535-7163

Senkal CE, Ponnusamy S, Rossi MJ, Bialewski J, Sinha D, Jiang JC, Jazwinski SM, Hannun YA, Ogretmen B (2007) Role of human longevity assurance gene 1 and C18-ceramide in chemotherapyinduced cell death in human head and neck squamous cell carcinomas. Mol Cancer Ther 6(2):712-722. https://doi.org/10.1158/ 1535-7163.MCT-06-0558

Sharma M et al (2014) In vitro anticancer activity of plant-derived cannabidiol on prostate cancer cell lines. Pharmacol Pharm. https:// doi.org/10.4236/pp.2014.58091

Shaw J, Costa-Pinheiro P, Patterson L, Drews K, Spiegel S, Kester M (2018) Novel sphingolipid-based cancer therapeutics in the personalized medicine era. Adv Cancer Res 140:327-366. https:// doi.org/10.1016/bs.acr.2018.04.016

Shrivastava A, Kuzontkoski PM, Groopman JE, Prasad A (2011) Cannabidiol induces programmed cell death in breast cancer cells by coordinating the cross-talk between apoptosis and autophagy.
Mol Cancer Ther 10(7):1161-1172. https://doi.org/10.1158/ $1535-7163$

Singer E, Judkins J, Salomonis N, Matlaf L, Soteropoulos P, McAllister S, Soroceanu L (2015) Reactive oxygen species-mediated therapeutic response and resistance in glioblastoma. Cell Death Dis 6(1):e1601. https://doi.org/10.1038/cddis.2014.566

Śledziński P, Zeyland J, Słomski R, Nowak A (2018) The current state and future perspectives of cannabinoids in cancer biology. Cancer Med 7(3):765-775. https://doi.org/10.1002/cam4.1312

Soderstrom K, Soliman E, Dross RV (2017) Cannabinoids modulate neuronal activity and cancer by $\mathrm{CB} 1$ and $\mathrm{CB} 2$ receptor-independent mechanisms. Front Pharmacol 8:720. https://doi.org/10. 3389/fphar.2017.00720

Soliman E, Henderson KL, Danell AS, Van Dross R (2016) Arachidonoyl-ethanolamide activates endoplasmic reticulum stressapoptosis in tumorigenic keratinocytes: Role of cyclooxygenase-2 and novel J-series prostamides. Mol Carcinog 55(2):117-130. https://doi.org/10.1002/mc.22257

Solinas M, Massi P, Cinquina V, Valenti M, Bolognini D, Gariboldi M, Monti E, Rubino T, Parolaro D (2013) Cannabidiol, a nonpsychoactive cannabinoid compound, inhibits proliferation and invasion in U87-MG and T98G glioma cells through a multitarget effect. PLoS One. 8(10):e76918. https://doi.org/10.1371/ journal.pone.0076918

Sreevalsan S, Joseph S, Jutooru I, Chadalapaka G, Safe SH (2011) Induction of apoptosis by cannabinoids in prostate and colon cancer cells is phosphatase dependent. Anticancer Res 31(11):3799-3807

Torres S, Lorente M, Rodríguez-Fornés F, Hernández-Tiedra S, Salazar M, García-Taboada E, Barcia J, Guzmán M, Velasco G (2011) A combined preclinical therapy of cannabinoids and temozolomide against glioma. Mol Cancer Ther 10(1):90-103. https://doi.org/ 10.1158/1535-7163.MCT-10-0688

Tutino V, Caruso MG, De Nunzio V, Lorusso D, Veronese N, Gigante I, Notarnicola M, Giannelli G (2019) Down-regulation of cannabinoid type 1 (CB1) receptor and its downstream signaling pathways in metastatic colorectal cancer. Cancers 11(5):708. https://doi.org/10.3390/cancers 11050708

Twelves C, Sabel M, Checketts D et al (2021) A phase 1b randomised, placebo-controlled trial of nabiximols cannabinoid oromucosal spray with temozolomide in patients with recurrent glioblastoma. Br J Cancer 124:1379-1387. https://doi.org/10.1038/ s41416-021-01259-3

Vara D, Salazar M, Olea-Herrero N et al (2011) Anti-tumoral action of cannabinoids on hepatocellular carcinoma: role of AMPKdependent activation of autophagy. Cell Death Differ 18:10991111. https://doi.org/10.1038/cdd.2011.32

Velasco G, Sánchez C, Guzmán M (2012) Towards the use of cannabinoids as antitumour agents. Nat Rev Cancer 12(6):436-444. https://doi.org/10.1038/nrc3247

Velasco G, Sánchez C, Guzmán M (2016) Anticancer mechanisms of cannabinoids. Curr Oncol 23:23-32. https://doi.org/10.3747/co. 23.3080

Vrechi TAM, Leão AHFF, Morais IBM et al (2021) Cannabidiol induces autophagy via ERK1/2 activation in neural cells. Sci Rep 11:5434. https://doi.org/10.1038/s41598-021-84879-2

Wang M, Zhao J, Zhang L, Wei F, Lian Y, Wu Y, Gong Z, Zhang S, Zhou J, Cao K, Li X, Xiong W, Li G, Zeng Z, Guo C (2017) Role of tumor microenvironment in tumorigenesis. J Cancer 8(5):761-773. https://doi.org/10.7150/jca.17648

Wu J (2019) Cannabis, cannabinoid receptors, and endocannabinoid system: yesterday, today, and tomorrow. Acta Pharmacol Sin 40(3):297-299. https://doi.org/10.1038/s41401-019-0210-3

Xian X, Huang L, Zhang B, Wu C, Cui J, Wang Z (2016) WIN $55,212-2$ inhibits the epithelial mesenchymal transition of 
gastric cancer cells via COX-2 signals. Cell Physiol Biochem 39(6):2149-2157. https://doi.org/10.1159/000447910

Xu D, Wang J, Zhou Z, He Z, Zhao Q (2015) Cannabinoid WIN55, 212-2 induces cell cycle arrest and inhibits the proliferation and migration of human BEL7402 hepatocellular carcinoma cells. Mol Med Rep 12(6):7963-7970. https://doi.org/10.3892/mmr. 2015.4477

Yang Y, Huynh N, Dumesny C, Wang K, He H, Nikfarjam M (2020) Cannabinoids inhibited pancreatic cancer via P-21 activated kinase 1 mediated pathway. Int J Mol Sci 21(21):8035. https:// doi.org/10.3390/ijms21218035

Yasmin-Karim S, Moreau M, Mueller R, Sinha N, Dabney R, Herman A, Ngwa W (2018) Enhancing the therapeutic efficacy of cancer treatment with cannabinoids. Front Oncol 24(8):114. https://doi. org/10.3389/fonc.2018.00114

Yu Z, Pestell TG, Lisanti MP, Pestell RG (2012) Cancer stem cells. Int J Biochem Cell Biol 44(12):2144-2151. https://doi.org/10. 1016/j.biocel.2012.08.022

Zhang Y, Zheng W, Shen K, Shen W (2018) $\Delta$ 9-tetrahydrocannabinol inhibits epithelial-mesenchymal transition and metastasis by targeting matrix metalloproteinase-9 in endometrial cancer. Oncol Lett 15(6):8527-8535. https://doi.org/10.3892/ol.2018.8407
Zhang X, Qin Y, Pan Z, Li M, Liu X, Chen X, Qu G, Zhou L, Xu M, Zheng Q, Li D (2019) Cannabidiol induces cell cycle arrest and cell apoptosis in human gastric cancer SGC-7901 cells. Biomolecules 9(8):302. https://doi.org/10.3390/biom9080302

Zhao P, Abood ME (2013) GPR55 and GPR35 and their relationship to cannabinoid and lysophospholipid receptors. Life Sci. https:// doi.org/10.1016/j.lfs.2012.06.039

Zhu LX, Sharma S, Stolina M, Gardner B, Roth MD, Tashkin DP, Dubinett SM (2000) Delta-9-tetrahydrocannabinol inhibits antitumor immunity by a CB2 receptor-mediated, cytokine-dependent pathway. J Immunol 165(1):373-380. https://doi.org/10.4049/ jimmunol.165.1.373

Zou S, Kumar U (2018) Cannabinoid receptors and the endocannabinoid system: signaling and function in the central nervous system. Int J Mol Sci 19(3):833. https://doi.org/10.3390/ijms1 9030833

Zuardi AW (2006) History of cannabis as a medicine: a review. Rev Bras Psiquiatr. https://doi.org/10.1590/S1516-44462006000200015

Publisher's Note Springer Nature remains neutral with regard to jurisdictional claims in published maps and institutional affiliations. 